\title{
Echinodermata da Baía de Todos os Santos e da Baía de Aratu (Bahia, Brasil)
}

\author{
Cynthia Lara de Castro Manso ${ }^{1,3}$, Orane Falcão de Souza Alves ${ }^{2}$ \& Luciana Ribeiro Martins $^{2}$ \\ ${ }^{1}$ Laboratório de Invertebrados Marinhos - LABIMAR, Núcleo de Ciências Biológicas, \\ Campus Prof. Alberto Carvalho, Universidade Federal de Sergipe - UFS, \\ Av. Vereador Olimpio Grande, s/n, CEP 49500-00, Itabaiana, SE, Brasil, www.campusitabaiana.ufs.br \\ ${ }^{2}$ Departamento de Zoologia, Laboratório de Geoecologia de Sedimentos Marinhos, \\ Instituto de Biologia, Campus Universitário de Ondina, Universidade Federal da Bahia - UFBA, \\ Rua Barão de Jeremoabo, s/n, CEP 40170-115, Salvador, BA, Brasil, \\ e-mail: orane@ufba.br, martins@ufba.br,http://www.biologia.ufba.br \\ ${ }^{3}$ Autor para correspondência: Cynthia Lara de Castro Manso,e-mail: cynthia@phoenix.org.br
}

MANSO, C.L.C., ALVES, O.F.S. \& MARTINS, L.R. 2008. Echinoderms from Todos os Santos Bay and Aratu Bay (Bahia, Brazil). Biota Neotrop. 8(3): http://www.biotaneotropica.org.br/v8n3/en/ abstract?article+bn02208032008.

\begin{abstract}
We present the results of the studies on biodiversity of Echinodermata (except Holothuroidea) from the Projects "Marine Environmental Evaluation of the Todos os Santos Bay - MAREMBA" (July/August 1996) and "Geoecology of the Benthic Infralitoral Communities of Todos os Santos Bay (BTS), Bahia, Brazil" (1997). A total of 33 species from 15 families were registered and re-described. The distribution of Ophiactis brasiliensis Manso, 1988 and Amphiodia trychna H.L. Clark, 1918 is extended to northwestern Brazil. The class Ophiuroidea was dominant in samples in terms of abundance and frequency of occurrence, in particular Amphiodia atra Stimpson, 1852, Amphipholis subtilis (Ljungman, 1867), Ophiactis lymani Ljungman, 1871 and Ophiostigma isocanthum (Say, 1825). The asteroid Oreaster reticulatus (Linnaeus, 1758) is considered vulnerable to human exploration and was scarce during the surveys. Other species found at BTS, such the asteroids Luidia clathrata (Say, 1825) and L. senegalensis (Lamarck, 1816) and the echinoid Eucidaris tribuloides (Lamarck, 1816) are included in the national list of threatened invertebrate species.
\end{abstract}

Keywords: echinoderms, taxonomy, distribution.

MANSO, C.L.C., ALVES, O.F.S. \& MARTINS, L.R. 2008. Echinodermata da Baía de Todos os Santos e da Baía de Aratu (Bahia, Brasil). Biota Neotrop. 8(3): http://www.biotaneotropica.org.br/v8n3/pt/ abstract?article+bn02208032008.

Resumo: Neste trabalho são registrados os equinodermos (exceto Holothuroidea) obtidos durante a execução do projeto "Marine Environmental Evaluation of the Todos os Santos Bay-MAREMBA" em julho/agosto de 1996 e durante o projeto "Geoecologia das comunidades bentônicas infralitorais da Baía de Todos os Santos (BTS), BA, Brasil: diversidade biótica e sedimentológica”, (1997). Um total de 33 espécies pertencentes a 15 famílias foram registradas e re-descritas. A distribuição de Ophiactis brasiliensis Manso, 1988 e Amphiodia trychna H.L. Clark, 1918 é estendida para a região nordeste do Brasil. A classe Ophiuroidea foi dominante nas amostragens em termos de abundância e freqüência de ocorrência, em particular as espécies Amphiodia atra Stimpson, 1852, Amphipholis subtilis (Ljungman, 1867), Ophiactis lymani Ljungman, 1871 e Ophiostigma isocanthum (Say, 1825). O asteróide Oreaster reticulatus (Linnaeus, 1758) é considerado vulnerável à exploração humana e foi escasso durante as coletas. Outras espécies encontradas na BTS, tais como os asteroides Luidia clathrata (Say, 1825) e L. senegalensis (Lamarck, 1816) e o equinóide Eucidaris tribuloides (Lamarck, 1816) figuram na lista nacional de espécies de invertebrados aquáticos ameaçados de extinção.

Palavras-chave: equinodermos, taxonomia, distribuição. 


\section{Introdução}

Os equinodermos constituem um dos grupos mais abundantes de animais dos fundos marinhos, nos quais os ofiuróides chegam muitas vezes a compor $90 \%$ da biomassa total nas regiões abissais (Hendler et al. 1995). No Brasil, até o momento foram registradas aproximadamente mais de 300 espécies de equinodermos (Tommasi 1999) das quais 73 espécies recentes e cinco fósseis foram assinaladas para o estado da Bahia (Rodovalho et al. 2003, Souza-Lima et al. 2003, Manso 2004, Magalhães et al. 2005, Manso 2007).

No Brasil, ao longo dos anos, têm se intensificado os estudos taxonômicos dos equinodermos recentes, em sua maioria nas regiões sul e sudeste (Manso, 1988a,b,c, Manso 1989, Manso 1991, Alburquerque 1991, Borges et al. 2002, 2006). De acordo com Lessius (2005), levantamentos faunísticos com a identificação das espécies são imprescindíveis, pois subsidiam a compreenção da estrutura, dinâmica e diversidade das comunidades de um dado local.

A região Nordeste ainda possui sua fauna de um modo geral pouco conhecida. O Estado da Bahia possui o maior litoral da costa brasileira, com ambientes que variam de recifes a baías passando por diversos tipos de praias. Entretanto, muito pouco é conhecido sobre a taxonomia do grupo exceto nas regiões sul (Manso, 2004) e sudeste do estado, onde está localizado o banco dos Abrolhos (Verril 1868, Tommasi \& Aron 1987, Albuquerque 1991, Manso 1993). Nas praias de Salvador são encontrados apenas registros sobre a ecologia das espécies (Santa-Isabel et al. 1996, Alves \& Cerqueira 2000, Martins et al. 2007a,b, Souto et al. 2007a,b), permanecendo grande parte da fauna do litoral norte baiano, praticamente desconhecida.

Com o objetivo principal de estudar a composição e distribuição das comunidades bentônicas na Baía de Todos os Santos (Bahia) e regiões adjacentes, foram realizadas amostragens em 1996 e coletas sistemáticas durante o ano de 1997 (Alves et al. 2006). Neste trabalho são apresentados os resultados obtidos referentes ao filo Echinodermata (exceto os da classe Holothuroidea), na forma de descrições. O conhecimento destas espécies deverá fornecer subsídios para elaboração de futuros projetos de proteção e manejo sustentável destas áreas.

\section{Material e Métodos}

\section{1. Área de estudo}

A Baía de Todos os Santos (BTS) é uma das maiores baías do Brasil, possuindo uma área aproximada de $1.100 \mathrm{~km}^{2}$ e apresentando $32 \mathrm{~km}$ de largura. Esta baía está localizada entre as coordenadas geográficas $12^{\circ} 35^{\prime} 30^{\prime \prime}-13^{\circ} 07^{\prime} 30^{\prime \prime} \mathrm{S}$ e $38^{\circ} 29^{\prime} 00^{\prime}-38^{\circ} 48^{\prime} 00^{\prime \prime} \mathrm{W}$. A Baía de Aratu é uma baía bem menor e está situada no interior da Baía de Todos os Santos. A Baía de Todos os Santos possui seu litoral bastante recortado, com aproximadamente $200 \mathrm{~km}$ de linha de costa, e apresenta uma série de enseadas, cabos, penínsulas e praias, compondo sua riqueza ambiental. Abriga, também, várias ilhas em seu interior, sendo a maior delas a de Itaparica, localizada na entrada da baía. No seu entorno estão situados importantes municípios do Estado da Bahia que fazem parte do denominado Recôncavo Baiano, destacando-se, entre eles, a capital Salvador (Silva et al. 1996, Germen et al. 1997) (Figura 1).

$\mathrm{Na}$ maior parte da baía o fundo é relativamente plano, com profundidades variando entre 2 e $10 \mathrm{~m}$, sendo que as maiores profundidades, por volta de $50 \mathrm{~m}$, estão situadas na região do canal Itaparica - Salvador (Macedo 1977, DHN 1984 - Carta Náutica 1110). Uma reavaliação detalhada sobre a sedimentação na Baía de Todos os Santos foi realizada por Lessa et al. (2000) e os aspectos oceanográficos, como circulação, são apresentados em Lessa et al. (2001). Esta importante baía vem sofrendo ao longo dos últimos

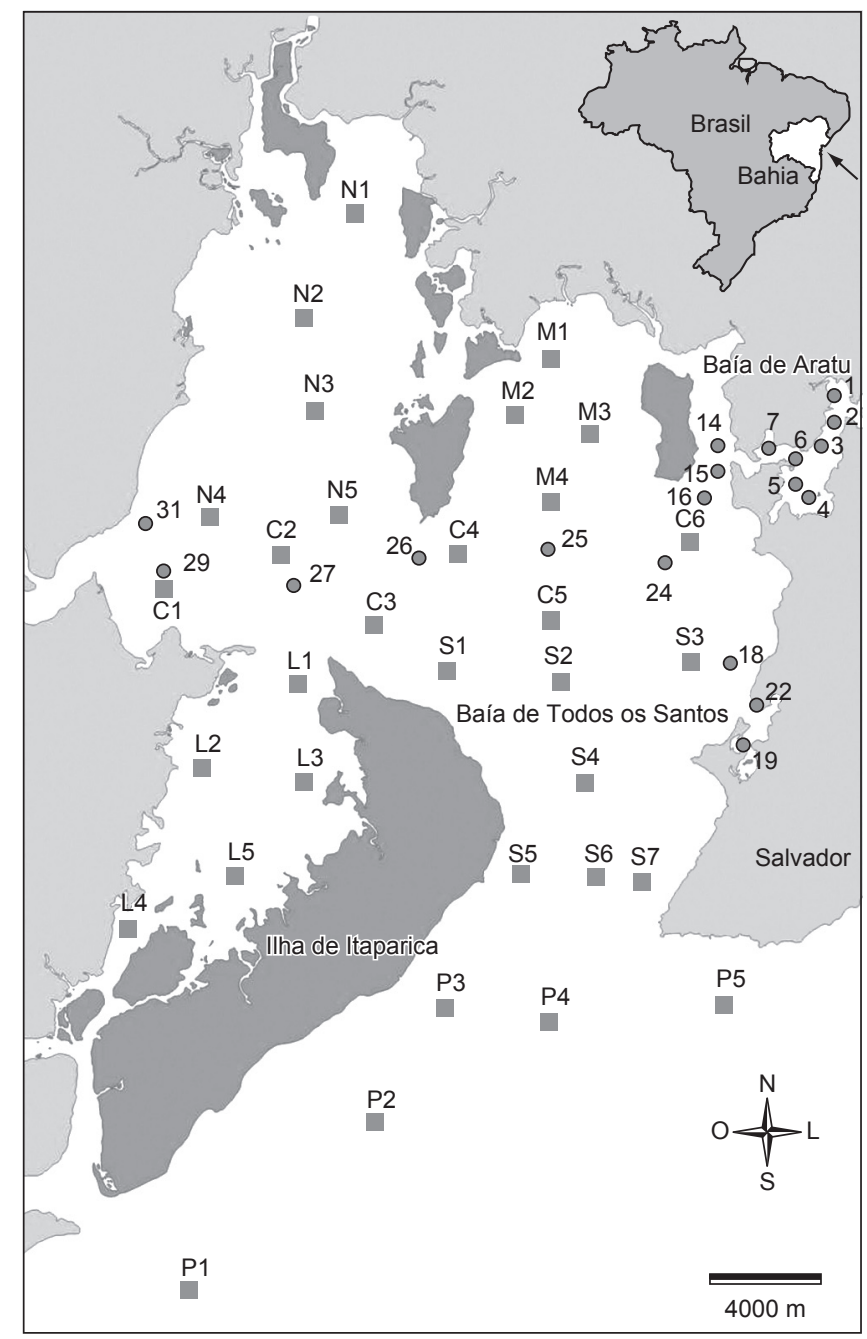

Figura 1. Mapa de localização das estações amostradas na Baía de Todos os Santos (BTS) e na Baía de Aratu. Letras e números conforme Tabela 1.

Figure 1. Map of the sampling stations in Todos os Santos Bay (BTS) and Aratu Bay. Letters and numbers like in Table 1.

tempos, uma forte ação antrópica, haja vista os diversos usos aos quais tem se destinado, entre os quais se sobressaem a pesca, o turismo, a utilização como via navegável para o escoamento de produção industrial e comercial, sendo Salvador o maior pólo turístico do Nordeste (Silva et al. 1996).

\section{Amostragem e análise}

As coletas para avaliação da fauna bentônica infralitoral da Baía de Todos os Santos foram realizadas em 1996 e mais detalhadamente em 1997. As coletas preliminares, entre junho e agosto de 1996, foram realizadas em conjunto com o Projeto "Marine Environmental Evaluation of the Todos os Santos Bay"- MAREMBA, onde foram amostrados sedimentos em 19 estações, localizadas no corpo principal da Baía de Todos os Santos (nove pontos) e ainda nas Baías de Aratu (oito pontos) e Itapagipe ou Enseada dos Tainheiros (dois pontos), localizadas na costa leste da Baía de Todos os Santos. Utilizou-se um busca-fundo tipo Van Veen de aço inox de $5 \mathrm{~L}$ de capacidade e três réplicas por ponto foram obtidas e lavadas em malha de $1 \mathrm{~mm}$ de abertura. O material foi fixado em formol neutro $5 \%$ e posteriormente triado em microscópio estereoscópico. Os exemplares de equinodermos foram separados para realização do estudo taxonômico. 
Tabela 1. Classificação do sedimento das estações (baseado nos Diagramas de Shepard e no teor de carbonato das amostras).

Table 1. Classification of the sediment from the stations (based on the Shepard Diagrams and on carbonate contend of the samples).

\begin{tabular}{|c|c|}
\hline Estação & Sedimento \\
\hline \multicolumn{2}{|l|}{ Área N } \\
\hline N1 & argila síltico-arenosa (siliciclástica) \\
\hline $\mathrm{N} 2$ & argila (siliciclástica) \\
\hline N3 & argila (siliciclástica) \\
\hline N4 & argila síltica (siliciclástica) \\
\hline N5 & argila (siliciclástica) \\
\hline \multicolumn{2}{|l|}{ Área M } \\
\hline M1 & argila síltica (siliciclástica) \\
\hline M2 & areia argilosa (siliciclástica) \\
\hline M3 & areia (carbonática) \\
\hline M4 & argila síltica (siliciclástica) \\
\hline \multicolumn{2}{|l|}{ Área C } \\
\hline $\mathrm{C} 1$ & argila síltico-arenosa (siliciclástica) \\
\hline $\mathrm{C} 2$ & argila síltica (siliciclástica) \\
\hline $\mathrm{C} 3$ & areia síltico-argilosa (siliciclástica) \\
\hline $\mathrm{C} 4$ & areia (carbonática) \\
\hline $\mathrm{C} 5$ & argila síltica (siliciclástica) \\
\hline C6 & argila síltica (siliciclástica) \\
\hline \multicolumn{2}{|l|}{ Área I } \\
\hline I1 & areia argilosa (carbonática) \\
\hline $\mathrm{I} 2$ & areia argilosa (carbonática) \\
\hline $\mathrm{I} 3$ & argila síltica (siliciclástica) \\
\hline I4 & Areia carbonática \\
\hline I5 & areia lamo-cascalhosa (carbonática) \\
\hline \multicolumn{2}{|l|}{ Área S } \\
\hline $\mathrm{S} 1$ & areia argilosa (siliciclástica) \\
\hline $\mathrm{S} 2$ & areia argilosa (siliciclástica) \\
\hline S3 & silte arenoso (siliciclástico) \\
\hline S4 & areia (siliciclástica) \\
\hline S5 & areia (siliciclástica) \\
\hline S6 & areia (siliciclástica) \\
\hline S7 & areia (siliciclástica) \\
\hline \multicolumn{2}{|l|}{ Área P } \\
\hline $\mathrm{P} 1$ & silte argiloso (siliciclástico) \\
\hline $\mathrm{P} 2$ & areia cascalhosa (carbonática) \\
\hline P3 & areia cascalhosa (siliciclástica) \\
\hline $\mathrm{P} 4$ & areia (siliciclástica) \\
\hline P5 & areia (carbonática) \\
\hline
\end{tabular}

Para as coletas realizadas em 1997 durante o projeto "Geoecologia das comunidades bentônicas infralitorais da Baía de Todos os Santos (BTS), BA, Brasil: diversidade biótica e sedimentológica”, a região de estudo foi dividida, de acordo com a sua morfologia, em seis grandes áreas, de tal maneira que diferentes ambientes sedimentológicos, com características oceanográficas distintas, fossem representados, visando uma melhor caracterização da biodiversidade. $\mathrm{O}$ total de 32 estações de coleta foi realizado em toda a baía e na plataforma continental adjacente (Figura 1).

As amostras foram obtidas utilizando-se uma embarcação de pesca com 7,65 m de comprimento, equipada com GPS (Garmim 75) e uma ecossonda de pesca - Humminbird, utilizada para avaliar a profundidade local. O sedimento de cada estação foi amostrado utilizando-se um busca-fundo tipo Van Veen 17 Lde capacidade e uma draga retangular de arrasto de $55 \mathrm{~cm}$ de profundidade, $45 \mathrm{~cm}$ de largura e $18 \mathrm{~cm}$ de altura, com saco interno de malha de metal de $5 \mathrm{~cm}$ de abertura de malha; três réplicas de busca-fundo e um arrasto foram realizados em cada estação. O material foi também lavado em peneira de $1 \mathrm{~mm}$ de malha, fixado em formol neutro $5 \%$ e posteriormente triado em microscópio estereoscópico. Os exemplares de equinodermos foram separados para realização do estudo taxonômico.

As análises sedimentológicas foram realizadas de acordo com Folk (1968) e Suguio (1973) através de peneiramento (para as frações grosseiras) e pipetagem (frações finas, menor que $0,062 \mathrm{~mm}$ ). A classificação do sedimento foi realizada utilizando-se o Diagrama Triangular de Shepard.

Os exemplares de Echinodermata foram conservados em álcool a $70 \%$ e identificados em nível específico segundo Hendler et al. (1995), Manso (1988a, 2004), Smith et al. (1995), Markov \& Soloovjev (2001) e Tommasi (1965, 1966, 1970a,b), sendo em seguida depositados na coleção do Museu de Zoologia da Universidade Federal da Bahia (MZUFBA).

\section{Resultados}

Foram registradas 33 espécies, pertencentes a 15 famílias distribuídas nas classes Crinoidea, Echinoidea, Asteroidea e Ophiuroidea.

Nas amostragens realizadas no ano de 1996, foram obtidos 21 exemplares de equinodermos em cinco estações entre os 19 pontos amostrados. Neste ano, os espécimes estiveram presentes em maior número na estação 18, representados pelo ofiuróide Amphiodia pulchella e pelo equinóide Cassidulus infidus, sendo que esta última espécie não ocorreu em 1997.

Nas coletas do ano de 1997, os equinodermos estiveram presentes em 29 estações das 32 estudadas. Os ofiuróides foram mais abudantes e freqüentes destacando-se Ophiostigma isocanthum (173 exemplares) ocorrendo na maioria das estações localizadas na região da entrada da Baía de Todos os Santos e do canal de Itaparica, onde a circulação de água é maior; Ophiactis lymani (105 exemplares) e Amphiodia atra (82 exemplares). Naquele ano foram registradas 32 espécies na Baía de Todos os Santos, com um total de 680 exemplares, obtidos principalmente por meio de draga de arrasto. Durante os trabalhos de campo de 1997, foram ainda realizadas coletas manuais através de mergulho, sendo recolhidos exemplares dos equinóides Encope emarginata e Leodia sexiesperforata, e dos asteróides Luidia senegalensis, L. clathrata e Oreaster reticulatus. Estas espécies não ocorreram nas coletas por meio do busca-fundo e nem da draga de arrasto.

As espécies Amphiodia atra e Amphipholis subtilis foram os ofiuróides mais freqüentes e bem distribuídos de um modo geral nas estações onde foram assinalados os sedimentos formados por argila síltica, silte argiloso ou silte arenoso, localizadas em sua maior parte no interior da Baía de Todos.

Naquelas estações das áreas P, S e I (Figura 1), foi observada maior abundância e diversidade de equinodermos.

$\mathrm{O}$ ambiente estudado mostrou-se bastante heterogêneo e 13 tipos texturais foram classificados. Três fundos de argila: argila (siliciclástica), argila síltica (siliciclástica) e argila síltico-arenosa (siliciclástica); dois fundos de silte: (silte argiloso (siliciclástico) e silte arenoso (siliciclástico); e oito tipos texturais de areia: areia argilosa (siliciclástica), areia argilosa (carbonática), areia sílticoargilosa (siliciclástica), areia (siliciclástica), areia (carbonática), areia lamo-cascalhosa (carbonática), areia cascalhosa (siliciclástica) e areia cascalhosa (carbonática). A classificação textural das estações pode ser vista na Tabela 1. 


\section{Lista de Táxons}

CLASSE CRINOIDEA MULLER, 1821

Comactinia echinoptera (Muller, 1840)

CLASSE ECHINOIDEA LESKE, 1778

Eucidaris tribuloides (Lamarck, 1816)

Lytechinus variegatus (Lamarck, 1816)

Leodia sexiesperforata (Leske, 1778)

Encope emarginata (Leske, 1778)

Cassidulus infidus Loven, 1874

Agassizia excentrica Agassiz, 1879

CLASSE ASTEROIDEA DE BRAINVILLE, 1830

Luidia clathrata (Say, 1825)

L. senegalensis (Lamarck, 1816)

Oreaster reticulatus (Linnaeus, 1758)

CLASSE OPHIUROIDEA GRAY, 1840

Ophiomyxa flaccida (Say, 1825)

Ophiocoma echinata (Lamarck, 1816)

Ophionereis squamulosa (Köehler, 1914)

Ophioderma brevispinum (Say, 1825)

Hemipholis elongata (Say, 1825)

Ophiactis lymani Ljungman, 1871

O. brasiliensis Manso, 1988

O. savignyi (Muller \& Troschel, 1842)

Amphiodia atra (Stimpson, 1852)

A. planispina (Martens, 1867)

A. riisei (Lütken, 1859)

A. trychna H.L. Clark, 1918

A. pulchella (Lyman, 1869)

Amphipholis januarii Ljungman, 1867

A. squamata (Delle Chiaje, 1928)

A. subtilis (Ljungman, 1867)

Ophiostigma isocanthum (Say, 1825)

Ophiocnida loveni (Ljungman, 1866)

Ophiophragmus luetkeni (Ljungman, 1871)

Ophionephthys limicola Lütken, 1869

Amphiura kinbergi (Ljungman, 1871)

A. palmeri Lyman, 1882

Ophiothrix angulata (Say, 1825)

\section{Taxonomia}

Classe Crinoidea Muller, 1821

Subclasse Articulata Zittel, 1879

Subordem Comatulina A.H. Clark, 1908

Superfamília Comasteracea H. Clark, 1908

Família Comasteridae A.H. Clark, 1908

Subfamília Comactiniinae A.H. Clark, 1909

1. Comactinia echinoptera (Muller, 1840)

(Figura 2a,b,c)

Material estudado: Dois espécimes obtidos na estação P2.

Descrição: Espécie com cirros curtos formados por nove segmentos, sem espinhos dorsais ou outros processos, terminando com uma espécie de espinho curvo e semelhante a uma garra. Com menos de 20 cirros ligados a uma placa centro dorsal plana. Com cinco braços ramificados totalizando 10 braços mais distintamente perceptíveis no adulto. As primeiras interbraquiais são muito curtas, estreitas e unidas lateralmente. As segundas interbraquiais são triangulares. A primeira articulação móvel (sizígia) está entre as braquiais três e quatro e a segunda entre

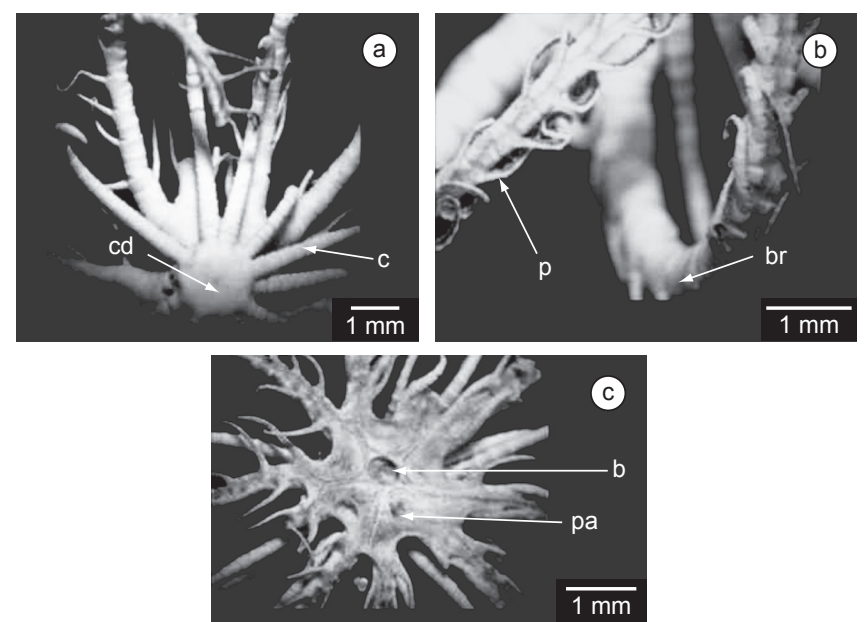

Figura 2. Comactinia echinoptera (Muller): a) Vista aboral da placa centro dorsal (cd), cirros (c) e braços; b) Vista dos braços (br) e pínulas (p); e c) Disco central mostrando a boca (b) e a papila anal (pa).

Figure 2. Comactinia echinoptera (Muller): a) Aboral view of centrodorsal plate (cd), cirri (c) and arms; b) Arms (br) and pinnules (p) view; and c) Central disc in oral view showing the mouth (b) and the anal papilla (pa).

as braquiais cinco e seis. Mais para a extremidade dos braços estas sizígias se apresentam em intervalos de aproximadamente cinco articulações musculares. Cone anal no centro do disco. Boca posicionada mais lateralmente no tegmen. Os quatro pares de pínulas mais próximos à boca em cada braço possuem um pente de dentes terminais. As pínulas restantes possuem espinhos marginais. Os braços são mais espessos na base e apresentam diferentes comprimentos. Aqueles braços situados mais próximos à boca tendem a ser mais longos.

Observações: Os exemplares foram obtidos a $12 \mathrm{~m}$ de profundidade em sedimento classificado como areia muito grossa. De acordo com Hendler et al. (1995), esta espécie permanece oculta durante o dia e, a noite, estende seus braços mais longos na direção da corrente, para se alimentar por meio de filtração. Durante este processo seu corpo e seus braços mais curtos permanecem escondidos.

Classe Echinoidea Leske, 1778

Sub-Classe Cidaroidea Claus, 1880

Ordem Cidaroida Claus, 1880

Família Cidaridae Gray, 1925

1. Eucidaris tribuloides (Lamarck, 1816)

(Figura 3a,b,c,d)

Material examinado: Quatro espécimes coletados nas estações: $\mathrm{S} 7, \mathrm{P} 2$ e P3.

Descrição: Carapaça arredondada, levemente achatada na direção oral-aboral. Espinhos primários espessos e cilíndricos, de tamanho médio, com a extremidade formada por uma pequena coroa de dentículos esbranquiçados. Muitas vezes estes espinhos possuem briozoários, algas e outros animais incrustantes ao seu redor. Os espinhos secundários são bastante comprimidos, bem menores que os espinhos primários e situados ao redor destes. Os espinhos secundários também são encontrados na região do periprocto e do perístoma. Os espinhos não são cobertos por tecido. As cinco zonas ambulacrais são levemente sinuosas e ladeadas por espinhos secundários. A região interambulacral é formada por duas fileiras de nove espinhos primários cada uma. As pedicelárias globíferas podem ser observadas na região do perístoma. 

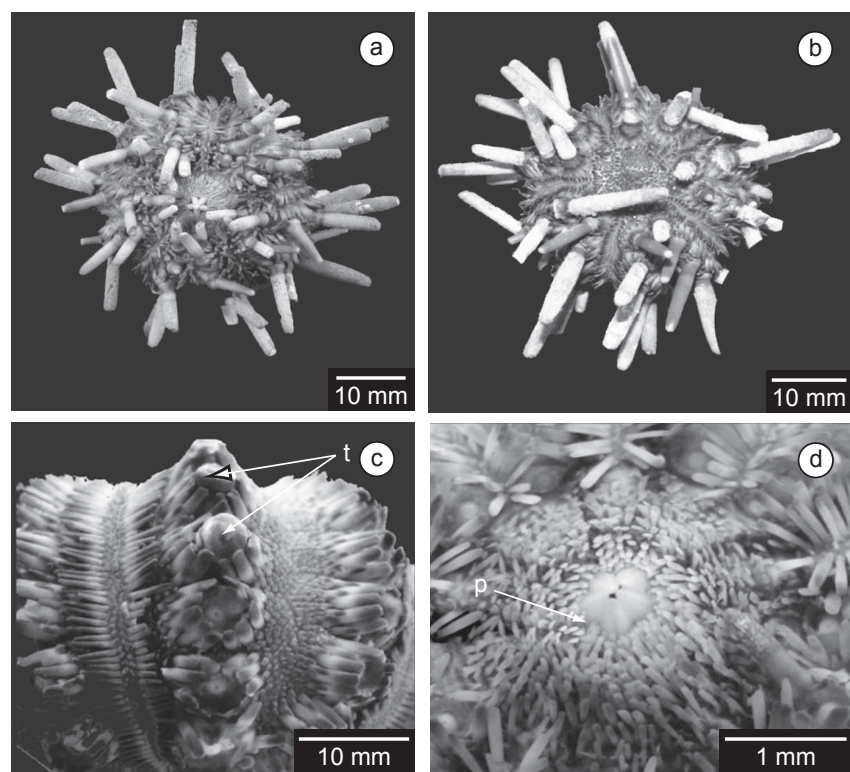

Figura 3. Eucidaris tribuloides (Lamarck): a) Vista oral; b) Vista aboral c) Vista lateral da carapaça, tubérculos (t); e d) perístoma (p).

Figure 3. Eucidaris tribuloides (Lamarck): a) Oral view; b) Aboral view; c) Lateral view of the test, tubercles (t); and d) peristome (p).

Observações: Esta espécie foi obtida entre 12 e $22,5 \mathrm{~m}$ de profundidade, em sedimentos formados por areia média e areia muito grossa.

Subclasse Euechinoidea Brown, 1860

Superordem Diadematacea Duncan, 1889

Ordem Temnopleuroida Mortensen, 1942

Família Toxopneustidade Troschel, 1872

1. Lytechinus variegatus (Lamarck, 1816)

(Figura 4a,b)

Material examinado: Sete espécimes coletados nas estações M3, I4, I5, S7, P2 e P3.

Descrição: Carapaça hemisférica, levemente achatada oralmente, coberta por espinhos razoavelmente curtos, delicados e afilados. Os tubérculos são pobremente desenvolvidos na região aboral da carapaça onde podem ser observadas algumas áreas sem espinhos. Perístoma em posição central na região oral em oposição ao periprocto na região aboral. Com pedicelárias globíferas com valvas alongadas visíveis a olho nu; possuem também pedicelárias tridentadas, ofiocéfalas e trifoliadas. A carapaça dos exemplares estudados possui a cor verde e os espinhos são esverdeados e púrpura.

Observações: Esta espécie foi obtida entre três e $22 \mathrm{~m}$ de profundidade em sedimentos formados por areia fina, areia média, areia muito grossa e grânulo.

De acordo com Hendler et al. (1995) a coloração da carapaça e dos espinhos desta espécie pode sofrer variações dentro de uma mesma população. Esta espécie é comumente encontrada em águas calmas e límpidas, não suportando águas túrbidas principalmente com silte em suspensão. De acordo com Allain (1978), esta espécie é sensível à poluição, que acarreta deformações na sua carapaça. Lytechinus variegatus também tem por hábito cobrir-se com restos de conchas filamentos de algas e detritos dos mais diversos como uma forma de camuflagem. Millot (1956), referindo-se a este tipo de comportamento, sugere que esta seja uma forma de filtrar a luz durante o dia.
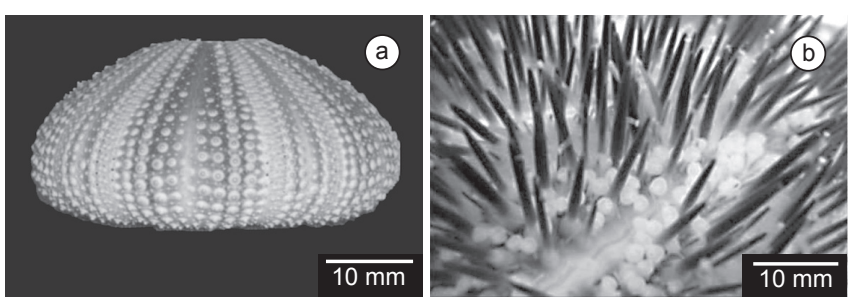

Figura 4. Lytechinus variegatus (Lamarck): a) Vista lateral da carapaça nua; e b) Vista dos espinhos da carapaça.

Figure 4. Lytechinus variegatus (Lamarck): a) Lateral view of the naked test; and b) View of the spines.

Superordem Gnathostomata Duncan, 1889

Ordem Clyperasteroida A. Agassiz, 1873

Subordem Scutellina Haeckel, 1896

Família Mellitidae Stefanini, 1911

1. Leodia sexiesperforata (Leske, 1778)

(Figura 5a,b,c)

Material examinado: Oito espécimes obtidos nas estações: S6, S7, P3 e P4.

Descrição: Carapaças muito comprimidas no sentido oral/ aboral, apresentando seis lúnulas fechadas, estreitas e alongadas. Cinco pétalas curtas e iguais. Disco apical com quatro gonoporos. Espinhos primários lisos e com a extremidade expandida. Com pedicelárias bivalves. O perístoma está localizado em posição central na região oral. $O$ periprocto também se encontra na região oral, entre o perístoma e a lúnula posterior mediana.

Observações: Leodia sexiesperforata foi coletada entre 12 e $24 \mathrm{~m}$ de profundidade, em sedimentos formados por areia média, areia muito grossa. Esta espécie é restrita a sedimentos biogênicos e carbonáticos e se alimenta de pequenas partículas de detritos que são selecionados por seus pódios (Telford \& Mooi, 1986).

2. Encope emarginata (Leske, 1778) (Figura 5d,e,f)

Material examinado: Um espécime coletado na estação M3.

Descrição: Carapaça arredondada e baixa medindo $125 \mathrm{~mm}$ de comprimento. Com a maior largura na região posterior ao disco apical, e com a maior altura, $10 \mathrm{~mm}$, na região apical; indivíduo, portanto adulto, com todas as lúnulas fechadas. Com cinco gonoporos bem visíveis em um disco apical monobasal. As três lúnulas posteriores são maiores do que as anteriores. A lúnula anterior mediana é menor do que as demais. Pétalas longas, fechadas a meia distância das lúnulas. Pétalas posteriores maiores do que as anteriores. Perístoma central na região oral. Periprocto também oral e posicionado a uma distância de 14,5 mm do perístoma, próximo ao início da lúnula posterior mediana. Espinhos ventrais da carapaça estreitos e afilados. Espinhos primários dorsais da carapaça finos e com a extremidade alargada semelhantes a palitos de fósforos. Espinhos marginais da carapaça e aqueles no interior das lúnulas maiores são mais robustos do que os demais.

Observações: O exemplar examinado foi obtido a $3 \mathrm{~m}$ de profundidade, em sedimento formado por areia média. Nos exemplares jovens as lúnulas encontram-se abertas.

Superordem Atelostomata Zittel, 1879

Ordem Cassiduloida Claus, 1880

Família Cassidulidae Agassiz \& Desor, 1847

1. Cassidulus infidus Loven, 1874

(Figura 6a,b,c,d)

Material examinado: Oito espécimes coletados na estação 18. 

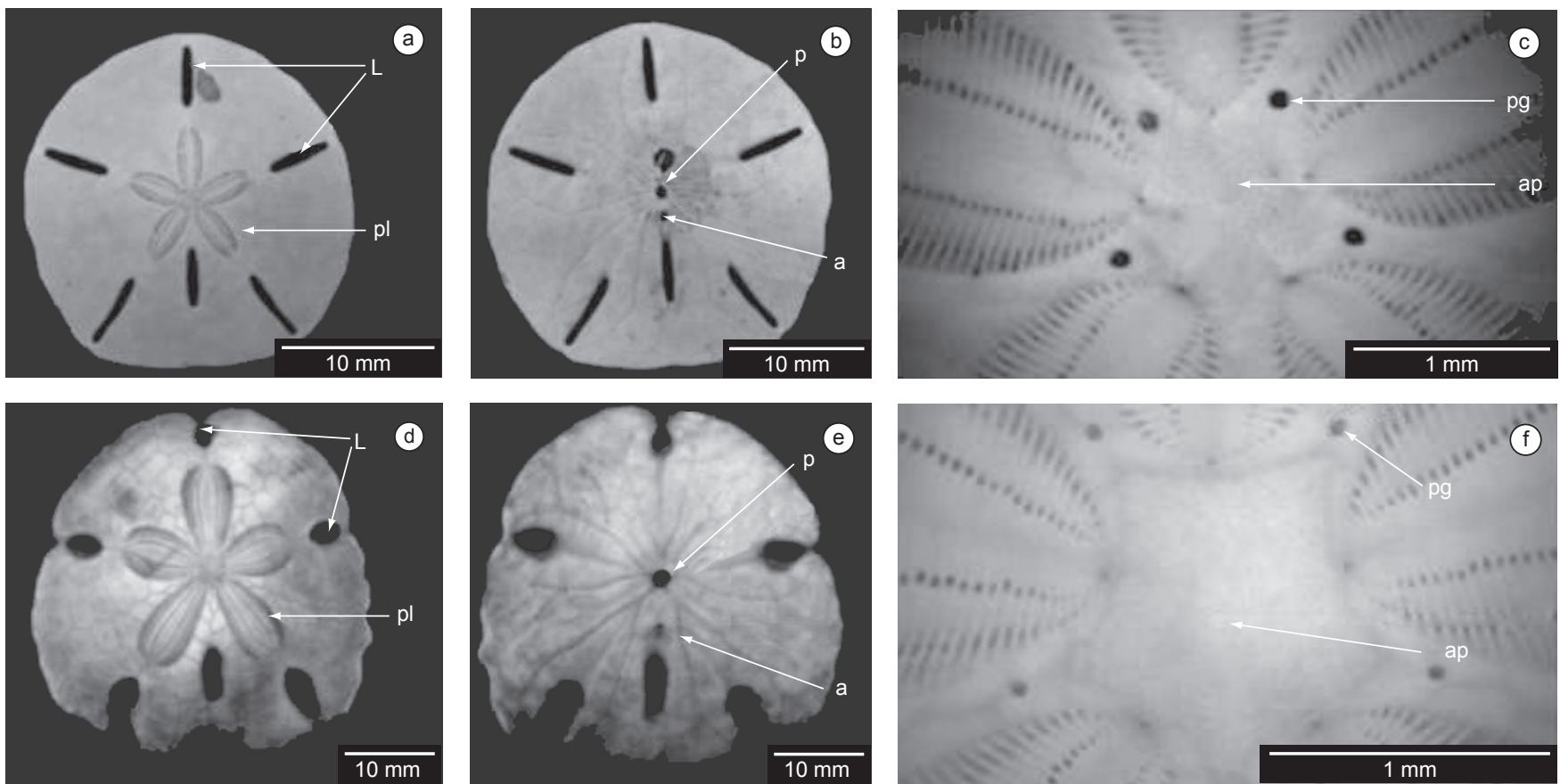

Figura 5. Leodia sexiesperforata (Leske): a) Vista aboral da carapaça, lúnulas (L) e pétalas (pl); b) Vista oral da carapaça, perístoma (p) e ânus (a); c) Sistema apical (ap) e poros genitais (pg). Encope emarginata (Leske): d) Vista aboral da carapaça, lúnulas (L) e pétalas (pl); e) Vista oral da carapaça, perístoma (p) e ânus (a); e f) Sistema apical (ap) e poros genitais (pg).

Figure 5. Leodia sexiesperforata (Leske): a) Aboral view of the test, lunules (L) and petals (pl); b) Oral view of the test, peristome (p) and anus (a); c) Apical system (ap) and genital pores (pg). Encope emarginata (Leske): d) Aboral view of the test, lunules (L) and petals (pl); e) Oral view of the test, peristome (p) and anus (a); and f) Apical system (ap) and genital pores (pg).

Descrição: Equinóides pequenos com carapaças entre 2,5 e $13 \mathrm{~mm}$ de comprimento, cobertas por espinhos primários e secundários curtos, levemente espatulados na região oral. $\mathrm{Na}$ região oral lateral os espinhos são longos e afilados. Na região mediana anterior oral e sobre as placas do plastrão a carapaça é recoberta apenas por espinhos secundários curtos. Sistema apical monobasal com quatro gonoporos localizados fora do centro, em direção à região anterior da carapaça. Pétalas subiguais abertas, ocupando $1 / 3$ da região aboral, formadas por duas fileiras de pares de poros. Periprocto na região posterior supra-ambital, localizado no interior de uma depressão. Perístoma pentagonal localizado na região mediana ventral. Filódios alargados anteriormente com os poros dispostos radialmente em duas fileiras externas de seis a sete poros e duas fileiras internas de dois a três poros. Espinhos bucais (bourrelet) longos fechando a abertura peristomial.

Observações: Exemplares encontrados a 3,5 m de profundidade, em fundos formados por areia média com fragmentos maiores.

Ordem Spatangoida Claus, 1876

Subordem Paleopneustina Markov \& Solovjev, 2001

Família Prenasteridae Lambert, 1905

1. Agassizia excentrica Agassiz, 1879

(Figura 6e,f)

Material examinado: Um espécime coletado na estação S4.

Descrição: Equinóides pequenos de formato oval; sistema apical fora do centro e mais próximo da região posterior. Os espinhos da carapaça são pequenos, afilados e vítreos, sendo os do plastrão espatulados e pouco maiores do que os demais. $\mathrm{O}$ ambúlacro III é raso, com poros pouco marcados, sendo mais visíveis os distais. As pétalas anteriores são mais longas do
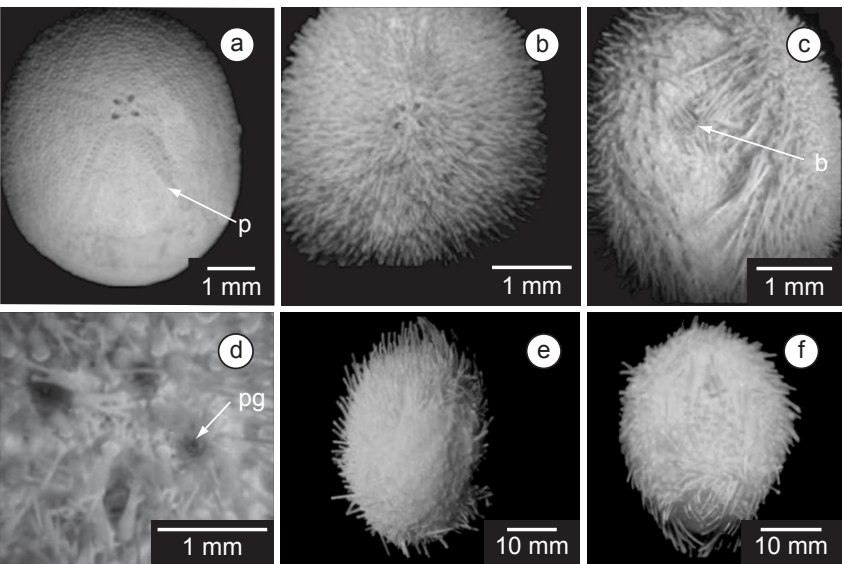

Figura 6. Cassidulus infidus (Loven): a) Vista aboral da carapaça nua e pétala (p); b) Vista aboral da carapaça com espinhos; c) Vista oral da carapaça e perístoma (b); d) Sistema apical e poro genital (pg). Agassizia excentrica (Agassiz): e) Vista aboral da carapaça; e f) Vista oral da carapaça.

Figure 6. Cassidulus infidus (Loven): a) aboral view of the naked test; b) aboral view of the test with spines; c) Oral view of the test and peristome (b); d) Apical system and genital pore (pg). Agassizia excentrica (Agassiz): e) aboral view of the test; and f) Oral view of the test.

que as posteriores, com os poros da série anterior diminutos. $\mathrm{O}$ periprocto está localizado na margem superior da região lateral posterior. As placas do periprocto são um pouco maiores próximos às bordas e diminuem em direção ao centro. O perístoma está na região oral anterior e possui o formato semi-lunar coberto por cerca de sete placas grandes. Esterno longo e triangular, recoberto por espinhos espatulados. 

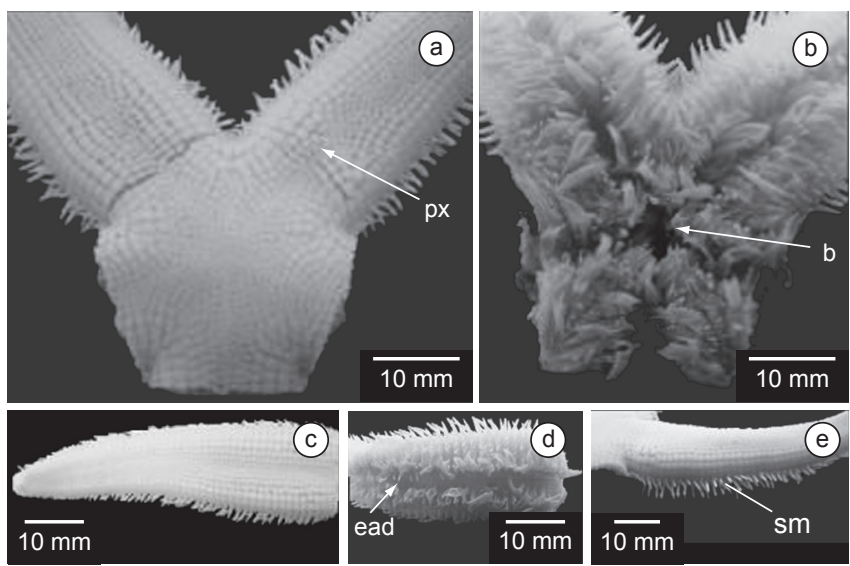

Figura 7. Luidia clathrata (Say): a) Vista aboral e paxilas (px); b) Vista ora e boca (b); c) Vista dorsal do braço; d) Vista ventral do braço e espinhos adambulacrais (ead); e e) Vista lateral do braço e espinhos marginais (sm).

Figure 7. Luidia clathrata (Say): a) Aboral view and paxillae (px); b) oral view and mouth (b); c) Dorsal arm view; d) Ventral arm view and adambulacral spines (ead); d) Lateral arm view; and e) marginal spines (sm).

Observações: Os exemplares foram coletados a uma profundidade de $56 \mathrm{~m}$ em sedimento formado por areia grossa.

Classe Asteroidea De Brainville, 1830

Ordem Platyasterida Spencer, 1951

Família Luidiidae Verril, 1899

1. Luidia clathrata (Say, 1825)

(Figura 7a,b,c,d,e)

Material estudado: Um espécime na estação P1.

Descrição: Espécie com cinco braços. Superfície adoral coberta por placas muito próximas umas das outras. Placas marginais quadrangulares e dispostas em séries longitudinais. Placas da região central dos braços menores do que as marginais e dispostas irregularmente. Cada braço possui uma margem de espinhos paxilares curtos que decrescem de comprimento em direção a sua extremidade. Estes espinhos são aproximadamente do mesmo tamanho que os espinhos paxilares laterais. A região oral possui espinhos pequenos nas placas actinolaterais. Os pódios não possuem ventosas.

Observações: O exemplar foi encontrado a $15 \mathrm{~m}$ de profundidade, em sedimento classificado como silte muito fino.

\section{Luidia senegalensis (Lamarck, 1816) (Figura 8a,b)}

Material examinado: Um espécime coletado na estação M3.

Descrição: Espécie com nove braços. A superfície adoral é coberta por placas de formato irregular a quadrangular. Estas placas estão dispostas muito próximas umas das outras. As paxilas são pequenas e numerosas. A região central desta estrela tem aparência circular.

Observações: Encontrada a 3,0 m de profundidade em sedimento formado por areia média.

Ordem Valvatida Perrier, 1884

Família Oreasteridae Fisher, 1911

1. Oreaster reticulatus (Linnaeus, 1758)

(Figura 8c,d,e)

Material estudado: Dois espécimes da estação P3.

Descrição: Espécie com cinco braços, robusta, de aparência carnosa e com a região central do corpo bastante inflada. A região adoral é revestida por placas espessas formando um desenho
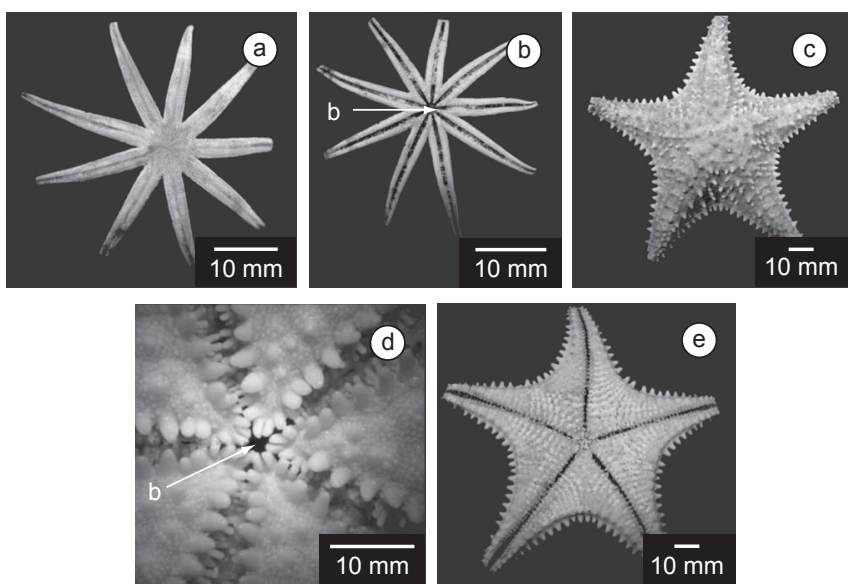

Figura 8. Luidia senegalensis (Lamarck): a) Vista aboral; b) Vista oral, boca (b). Oreaster reticulatus (Linnaeus): c)Vista aboral; d)Vista das mandíbulas na região bucal; e e) Vista oral.

Figure 8. Luidia senegalensis (Lamarck): a) aboral view; b) Oral view, mouth (b). Oreaster reticulatus (Linnaeus): c) aboral view; d) Jaw view on the mouth; and e) oral view.

reticular. Em cada uma destas placas pode ser observado um tubérculo pontiagudo. As placas superomarginais apresentam tubérculos maiores semelhantes a espinhos. A região oral é recoberta por grânulos. As placas actinolaterais possuem espinhos grandes, achatados e com pontas arredondadas, dispostos em séries duplas.

Observações: A espécie foi obtida a profundidade de $16 \mathrm{~m}$ sobre sedimento formado por areia muito grossa

Classe Ophiuroidea Gray, 1840

Subclasse Ophiuridea Gray, 1840

Ordem Ophiurida Muller \& Troschel, 1840

Subordem Ophiomyxina Fell, 1962

Família Ophiomyxidae Ljungman, 1867

1. Ophiomyxa flaccida (Say, 1825)

(Figura 9a,b,c)

Material estudado: Três espécimes provenientes da estação $\mathrm{C} 2$.

Descrição: Disco levemente pentagonal coberto por tegumento, apresentando as regiões interradiais marginais com até 12 escamas, sendo que as medianas são menores do que as mais laterais. Escudos radiais mais longos do que largos e alargados na margem proximal interna. A região interradial apresenta-se também recoberta por tegumento. As fendas bursais ultrapassam levemente a região mediana interradial oral. Os escudos orais são ovais e os escudos adorais estreitos e curtos. Com três a quatro papilas orais comprimidas, alargadas e com dentículos afilados nas extremidades. Braços não muito longos. Placas aborais alongadas e simples, algumas fragmentadas. Com cinco espinhos braquiais comprimidos e com dentículos.

Observações: Coletados a $16 \mathrm{~m}$ de profundidade em fundo de areia muito grossa. Os indivíduos desta espécie são ativos durante a noite e se alimentam abocanhando pedaços grandes de alimentos como algas, esponjas e detritos coletados através de movimentos laterais dos braços (Hendler et al. 1995).

Superfamília Ophiocomidea Ljungman, 1867

Família Ophiocomidae Ljungman, 1867

Subfamília Ophiocominae Ljungman, 1867

1. Ophiocoma echinata (Lamarck, 1816)

(Figura 10a,b,c). 

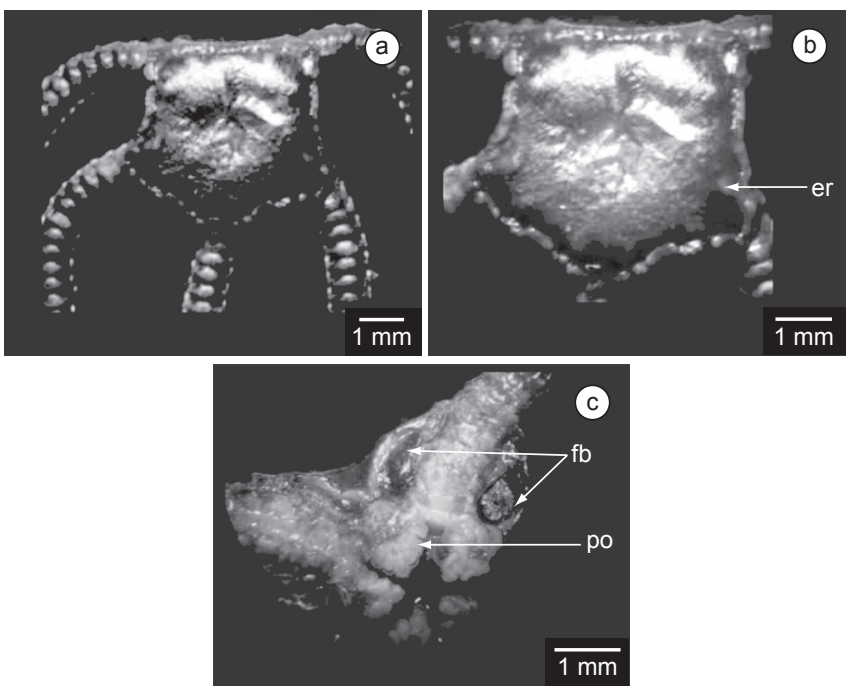

Figura 9. Ophiomyxa flaccida (Say): a) Vista aboral; b) Vista aboral e escudo radial (er); e c) Vista oral, fendas bursais (fb) e papilas orais (pa).

Figure 9. Ophiomyxa flaccida (Say): a) Aboral view; b) Aboral view and radial shield (er); and c) Oral view, bursal slit (fb) and oral papillae (pa).
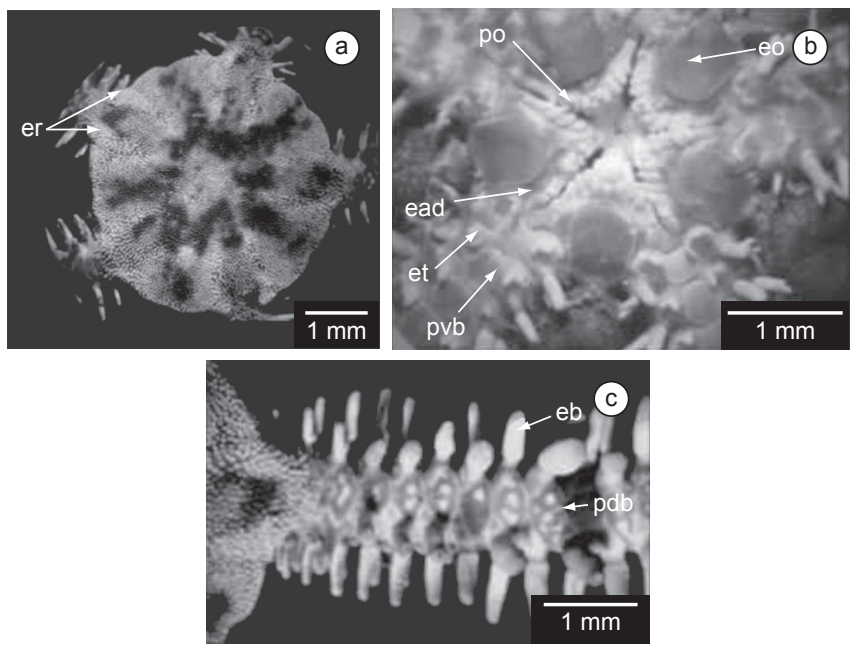

Figura 10. Ophiocoma echinata (Lamarck): a) Vista aboral do disco e escudos radiais (er); b) Detalhes da armação bucal e base dos braços, placa oral braquial (pvb), escama tentacular (et), escudo oral (eo), escudo adoral (ead) e papila oral (po); e c) Detalhe da superfície aboral do braço e espinhos, placa aboral (pdb) e espinhos (eb).

Figure 10. Ophiocoma echinata (Lamarck): a) Aboral view of the disc and radial shield (er); b) Detail of the oral frame and arm base, oral arm plate (pvb), tentacle scale (et), oral shield (eo), adoral shield (ead) and oral papilla (po); and c) Detail of aboral surface of the arm and spines, aboral plate (pdb) and spines (eb).

Material estudado: Um espécime obtido na estação P1.

Descrição: Disco arredondado, com a região aboral e escudos radiais cobertos por grânulos. Região oral interradial interna desprovida de grânulos, com as fendas bursais abertas e margeadas por escamas. Escudos orais com a forma aproximada de um triângulo. O par mandibular levemente separado na região distal, com quatro papilas orais de cada lado. Com um feixe de papilas dentarias no ápice das mandíbulas. Braços não muito longos, mas afilados em direção à extremidade. Com três espinhos braquiais no primeiro segmento e dois no segundo; nos segmentos seguintes são observados diferentes números de espinhos braquiais. Os espinhos braquiais aborais podem se tornar espessos e bulbosos em direção à metade do braço. Com duas escamas tentaculares.

Observações: Esta espécie foi encontrada a $15 \mathrm{~m}$ de profundidade em sedimento composto por silte muito fino.

Família Ophionereididae Ljungman, 1867

1. Ophionereis squamulosa (Köehler, 1914)

(Figura 11a,b,c)

Material estudado: Cinco espécimes coletados na estação P2.

Descrição: Disco geralmente pentagonal coberto por escamas pequenas. Escudos radiais pequenos e separados por várias escamas. Região interradial oral coberta por escamas semelhantes àquelas da face aboral. Fendas bursais largas e com as bordas cobertas por escamas e papilas genitais robustas. Escudos orais sub-triangulares. A madreporita é maior que os demais escudos. Escudos adorais estreitos anteriormente e alargados distalmente. Mandíbulas com cinco a seis papilas orais. Braços não muito alongados. Placas aborais mais largas na região anterior e mais estreitas na região posterior. Placas aborais acessórias ou suplementares bem desenvolvidas, tocando a região anterior da placa dorsal vizinha. Com uma grande escama tentacular. Com três espinhos braquiais mais longos do que o segmento do braço, comprimidos na direção aboral-oral, com as pontas arredondadas.

Observações: Ophionereis squamulosa foi encontrada a $12 \mathrm{~m}$ de profundidade em sedimento formado por areia muito grossa. Quanto à coloração, característica marcante deste gênero, é aparentemente "borrada" sem a linha perfeita de seu congênere Ophionereis reticulata.

Infraordem Ophiodermatinae Smith, Paterson \& Lafay, 1995 Família Ophiodermatidae Ljungman, 1867

1. Ophioderma brevispinum (Say, 1825)

(Figura 12a,b,c,d)

Material estudado: Dois espécimes coletados na estação P2.

Descrição: Disco pentagonal coberto por grânulos que recobrem os escudos radiais. Com quatro fendas bursais na região oral interradial posicionada ao lado dos braços. Escudos orais de contorno oval. Escudos adorais sem grânulos. Com sete a oito papilas orais de cada lado das mandíbulas. Braços pouco afilados em direção à extremidade. Com oito a nove espinhos braquiais pontiagudos. Duas escamas tentaculares.

Observações: Encontrada sob rochas em sedimentos formados por areia muito grossa.

Subordem Ophiurina Muller \& Troschel, 1840

Infraordem Gnatophiurina Matsumoto, 1915

Superfamília Gnathophiuridea Matsumoto, 1915

Família Ophiactidae (Matsumoto, 1915)

1. Hemipholis elongata (Say, 1825)

(Figura 13a,b,c)

Material estudado: Oito espécimes coletados nas estações: 6, M2, I1, S5.

Descrição: Disco arredondado com reentrâncias radiais e coberto por escamas pequenas e arredondadas na região dorsal, sem escamas na região ventral. Em cada lado das reentrâncias radiais podem ser observados de um a quatro espinhos. Escudos radiais grandes, com as bordas externas curvas, e separados por três escamas. Região oral interradial coberta por tegumento fino, onde muitas vezes são encontrados vários corpúsculos calcários espalhados mais frequentemente na região interradial mediana. Fendas bursais ladeadas por papilas genitais espiniformes. Escu- 

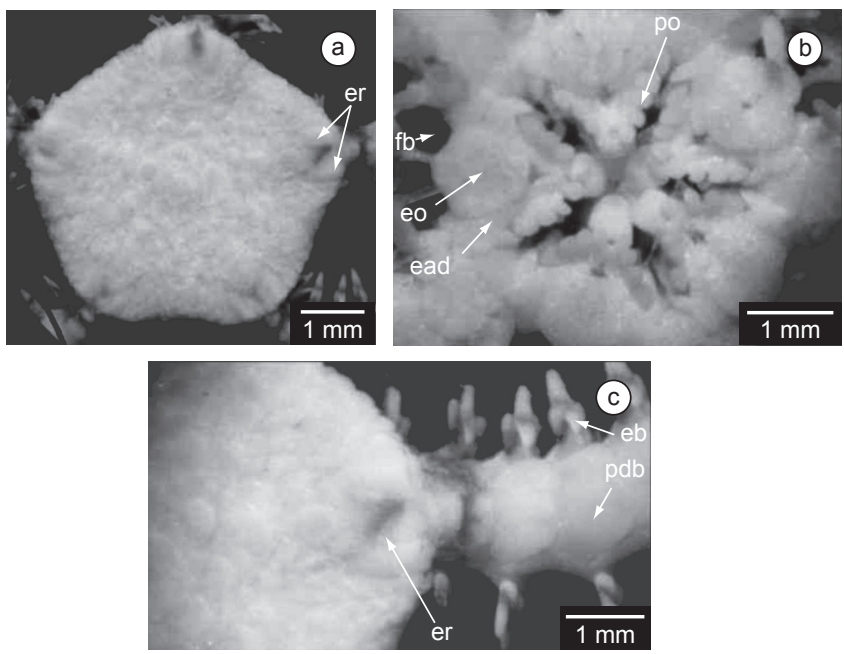

Figura 11. Ophionereis squamulosa (Köehler): a) Vista aboral do disco e escudos radiais (er); b) Vista oral, fendas bursais (fb), escudo oral (eo), escudo adoral (ead) e papila oral (po); c) Vista aboral do disco e braço, escudo radial (er), placa aboral (pdb) e espinho (eb).

Figure 11. Ophionereis squamulosa (Köehler): a) Aboral view of the disc and radial shields (er); b) Oral view, bursal slit (fb), oral shield (eo), adoral shield (ead) and oral papilla (po); and c) Aboral view of the disc and arm, radial shield (er), aboral plate (pdb) and spine (eb).
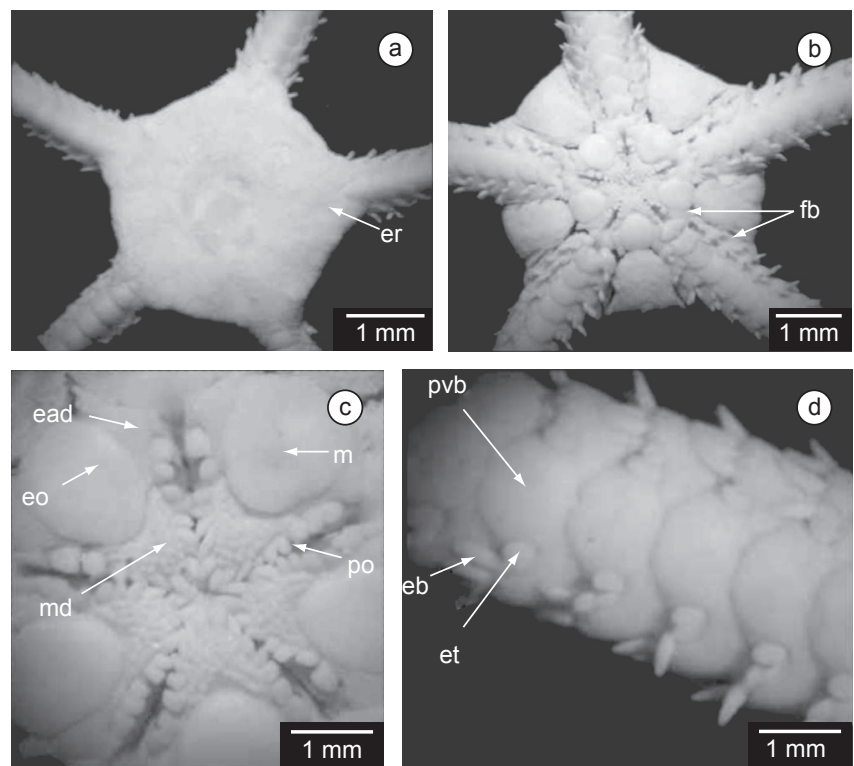

Figura 12. Ophioderma brevispinum (Say): a) Vista aboral do disco e escudo radial (er); b) Vista oral do disco, base dos braços e fendas bursais (fb); c) Detalhe da armação oral, madreporita (m), escudo oral (eo), escudo adoral (ead), mandíbula (md) e papilas orais (po); e e) Detalhes das placas orais do braço (pvb), escamas tentaculares (et) e espinhos (eb).

Figure 12. Ophioderma brevispinum (Say); a) Aboral view of the disc and radial shield (er); b) Oral view of the disc, arm base and bursal slits (fb); c) Details of oral frame, madreporite (m), oral shield (eo), adoral shield (ead), jaw (md) and oral papillae (po); and e) Details of the oral plates of the arm (pvb), tentacle scales (et) and spines (eb).

dos orais ovalados. Escudos adorais alargados na região distal. Madreporito maior que os demais escudos orais. Mandíbulas curtas, unidas, com uma forte depressão mediana. Com uma papila infradental na região proximal das mandíbulas e com uma papila oral distal espatulada de cada lado das mandíbulas. Braços longos
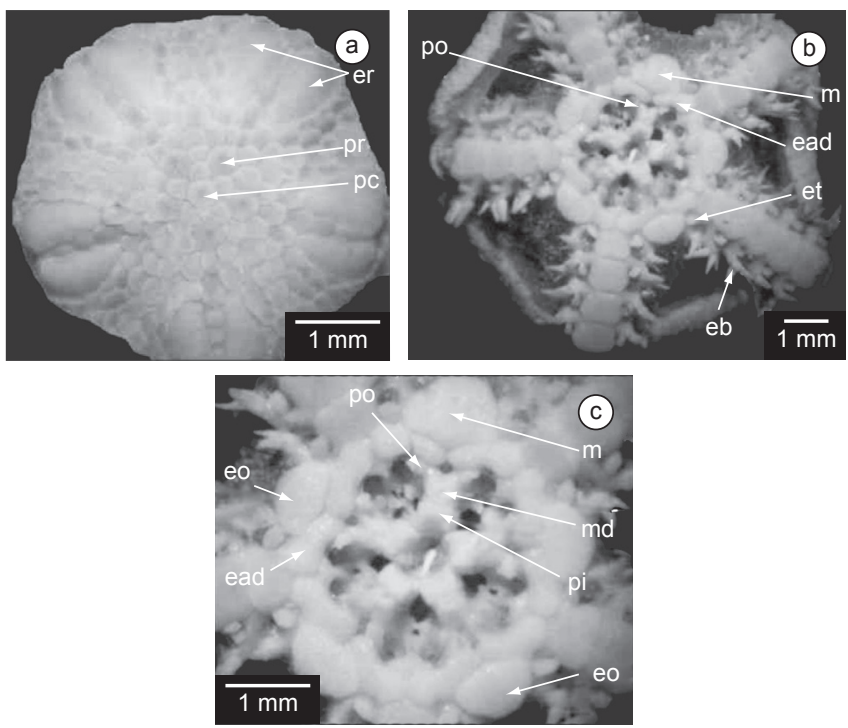

Figura 13. Hemipholis elongata (Say): a) Vista aboral, escudos radiais (er), placas primárias radiais (pr) e placa central (pc); b) Vista oral do disco onde espinho do braço (eb), escama tentacular (et), madreporita (m), escudo adoral (ead) e papila oral (po); e c) Detalhes da armação bucal, madreporita (m), escudo adoral (ead), mandíbula (md), papila oral (po) e papila infradental (pi).

Figure 13. Hemipholis elongata (Say): a) Aboral view, radial shiels (er), primary radial plates (pr) and central plate (pc); b) Oral view of the disc, arm spines (eb), tentacle scale (et), madreporite (m), adoral shield (ead) and oral papilla (po); and c) Details of the oral frame, madreporite (m), adoral shields (ead), jaw (md), oral papilla (po) and infradental papillae (pi).

e com as placas aborais mais largas do que longas. Placas orais também mais largas do que longas. Com uma escama tentacular e três espinhos braquiais.

Observações: Hemipholis elongata foi coletado entre 18 e $24 \mathrm{~m}$ de profundidade em sedimentos compostos por silte médio, areia muito fina e areia média. Indivíduos com gônadas maduras foram observados em abril de 1997. De acordo com Hendler et al. (1995), esta é uma espécie gregária vivendo em agrupamentos de vinte a trinta indivíduos, em fundos moles compostos por sedimentos finos. O oxigênio transportado pela hemoglobina pode compensar a ausência de bursas respiratórias, capacitando esta espécie a sobreviver em sedimentos pobremente oxigenados (Hendler et al. 1995). Hemipholis elongata é conhecida ainda por viver em ambientes eutróficos ou poluídos, onde pode acumular substâncias tóxicas como mercúrio tóxico (Hendler et al. 1995). Esta espécie pode servir de alimento para espécies de peixes como o baiacu Spheroides testudineous Linnaeus (Manso \& Farias 1999).

\section{Ophiactis lymani Ljungman, 1871}

(Figura 14a,b)

Material estudado: 106 espécimes coletados nas estações: I1, I2, I4, I5, S4 e S7.

Descrição: Disco arredondado com escamas grandes, irregulares e sem espinhos na face aboral. Escamas primárias evidentes. Escudos radiais mais longos do que largos com a margem externa curva, e separados por até quatro escamas. Com um espinho atrás dos escudos radiais. Região interradial oral coberta por escamas menores do que as da região aboral e apresentando nos espaços interradiais três a quatro espinhos afilados. Escudos orais sublosangulares. Escudos adorais alargados distalmente. Com uma papila oral de cada lado da mandíbula e uma infradental retan- 
gular. Com cinco a seis braços curtos. Placas aborais braquiais flabeliformes. Placas orais dos braços pentagonais. Com uma escama tentacular grande. Três espinhos braquiais.

Observações: Esta espécie foi obtida entre 1,5 e $56 \mathrm{~m}$ de profundidade em sedimentos formados por silte grosso, areia fina, areia média, areia grossa e grânulo.

\section{Ophiactis brasiliensis Manso, 1988}

(Figura $14 \mathrm{c}, \mathrm{d}, \mathrm{e}$ )

Material estudado: 7 espécimes coletados nas estações I2 e I5.

Descrição: Disco arredondado coberto por escamas grandes de formato irregular e finamente granuladas, podendo ocorrer junto a elas escamas bem menores principalmente próximo à centro dorsal, em fileira única, dupla ou tripla entre os pares de escudos radiais. Escudos radiais mais longos do que largos, com sua maior largura próxima à região distal. Região interradial oral totalmente escamada, com alguns espinhos esparsos. Escudos orais pequenos e sublosangulares. Escudos adorais alargados no bordo distal e não contíguos na região proximal. Com uma pequena papila oral grande de cada lado da mandíbula e uma papila infradental retangular. Braços em número de cinco a seis, medindo de duas a três vezes o diâmetro do disco. Placas braquiais aborais quase elípticas e cobertas por fina granulação. Placas laterais bem desenvolvidas. Placas orais também com fina granulação e com leve concavidade no bordo distal. Com quatro espinhos braquiais rômbicos e cobertos por dentículos. O espinho inferior é menor que os demais; os medianos um tanto comprimido; o superior é mais afilado e seu tamanho diminui em direção a extremidade do braço até desaparecer por volta do $7^{\circ}$ ao $12^{\circ}$ segmentos. Poro tentacular grande e com uma escama tentacular oval.

Observações: Ophiactis brasiliensis foi coletada entre 1,5 e $5 \mathrm{~m}$ de profundidade em sedimentos formados por silte grosso e grânulo. Esta espécie possui uma tonalidade amarelada, com um padrão de manchas variadas verde oliva e azuladas sobre o disco e a região aboral dos braços. A região oral dos braços e a armação oral são esbranquiçadas, distinguindo esta espécie das demais aqui citadas.

4. Ophiactis savignyi (Muller \& Troschel, 1842)

(Figura 14f,g,h)

Material estudado: Sete espécimes coletados nas estações: I2, I5 e P2.

Descrição: Disco arredondado coberto por escamas e alguns espinhos dispersos, tanto na face aboral como na face oral. Escudos radiais grandes, triangulares, excedendo a metade do raio do disco, unidos e algumas vezes separados em sua porção proximal. Região interradial oral coberta por escamas e espinhos dispersos. Fendas bursais largas e ladeadas por papilas genitais desenvolvidas. Escudos orais ovais. Escudos adorais grandes e alargados. Com uma a três (mas freqüentemente duas) papilas orais espatuladas na região distal da mandíbula. Com uma papila infradental. Com seis braços no jovem e cinco braços em alguns exemplares adultos. Placas aborais dos braços mais largas do que longas cobertas por fina granulação. Placas orais mais ou menos tão largas quanto longas. Uma escama tentacular. Com cinco a seis espinhos braquiais denticulados.

Observações: Esta espécie foi encontrada em profundidades entre 1,5 e $12 \mathrm{~m}$ em sedimentos formados por silte grosso, areia muito grossa e grânulo. Ophiactis savignyi é uma espécie fissípara que é normalmente encontrada associada a esponjas e algas vivendo em grandes densidades de indivíduos. Os jovens normalmente dividem-se por fissiparidade e os adultos possuem cinco ou seis braços e reproduzem-se tanto sexuada como assexuadamente.
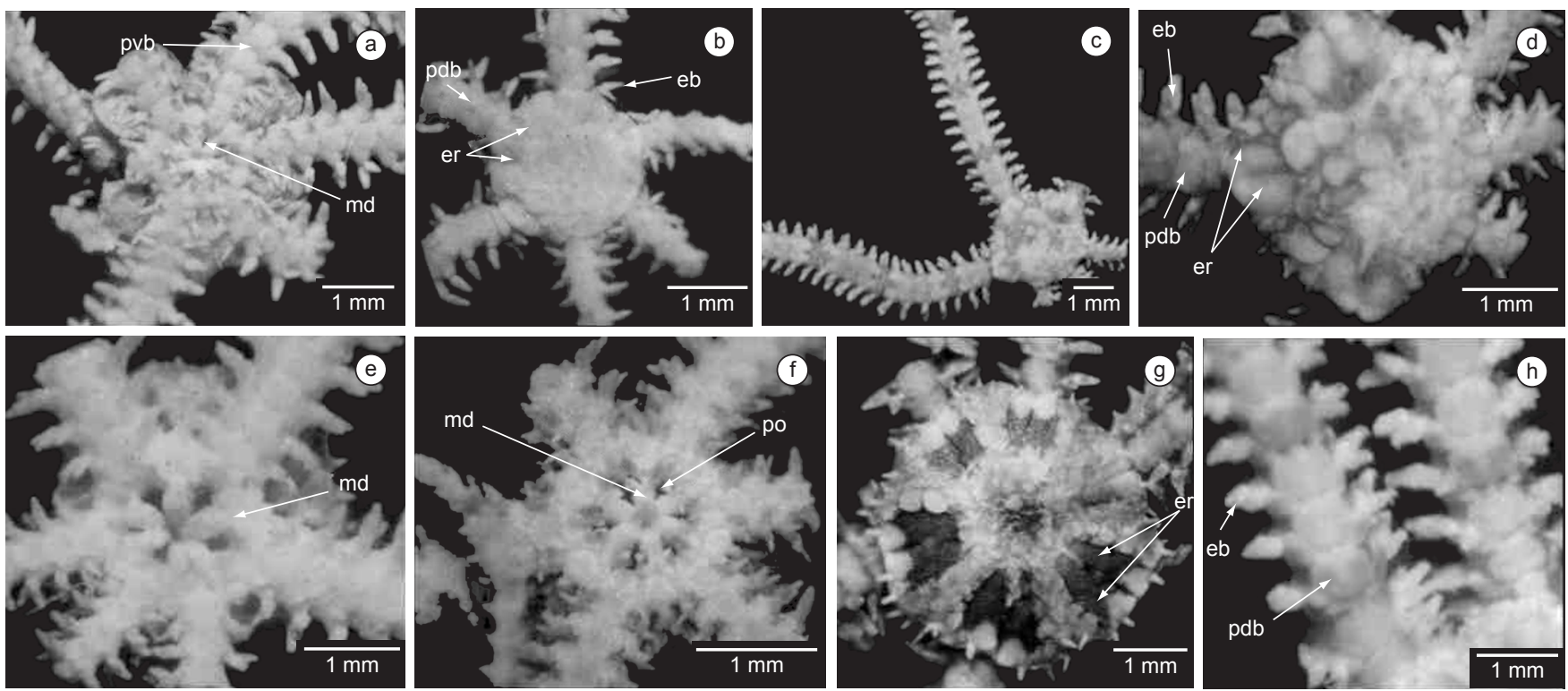

Figura 14. Ophiactis lymani Ljungman: a) Vista oral, placas orais do braços (pvb) e mandíbula (md); b) Vista aboral, placas aborais dos braços (pdb), espinhos (eb) e escudos radiais (er). Ophiactis brasiliensis Manso: c) Vista aboral; d) Detalhes da superfície aboral do disco, escudos radiais (er), placas aborais dos braços (pdb) e espinhos (eb); e) Vista oral e mandíbula (md). Ophiactis savignyi (Muller \& Troschel): f) Vista oral, mandíbulas (md) e papilas orais (po); g) Detalhes da superfície aboral do disco e escudos radiais (er); e h) Detalhes das placas aborais dos braços (pdb) e espinhos (eb).

Figure 14. Ophiactis lymani Ljungman: a) Oral view, oral arm plates (pvb) and jaw (md); b) Aboral view, aboral arm plates (pdb), spines (eb) and radial shields (er). Ophiactis brasiliensis Manso: c) Aboral view; d) Details of the aboral surface of the disc, radial shields (er), aboral arm plates (pdb) and spines (eb); e) Oral view and jaw (md). Ophiactis savignyi (Muller \& Troschel): f) Oral view, jaw (md), and oral papillae (po); g) Details of the aboral surface of the disc and radial shields (er); and h) Details of the aboral plates of the arm and spines (eb). 
Família Amphiuridae Ljungman, 1867

1. Amphiodia atra (Stimpson, 1852)

(Figura 15a,b,c,d)

Material estudado: 68 coletados nas estações, 6, N4, M2, C3, C4, C5, I1, I2, I5, S5, P2 e P5.

Descrição: Disco arredondado coberto por escamas com as placas primárias visíveis no indivíduo adulto. Escudos radiais um pouco mais longos do que largos, com o bordo distal curvo e com uma, duas, três ou até quatro escamas intercaladas entre os escudos radiais de cada par. Na região mediana, entre os pares de escudos radiais, há uma faixa de escamas maiores do que as demais. Escamas da região oral do disco imbricadas e menores que as aborais. Escudos orais losangulares. Madreporita semioval. Escudos adorais alargados distalmente. Com duas papilas orais triangulares, sendo que a externa é o dobro do tamanho da interna. Papilas infradentais retangulares. Braços longos com até 12 vezes o diâmetro do disco. Placas aborais proximais mais largas do que longas. Placas orais semi-pentagonais. Com duas escamas tentaculares e três espinhos braquiais afilados dos quais o superior é o mais afilado e menor do que os demais.

Observações: Os exemplares foram obtidos entre 1,5 e $48 \mathrm{~m}$ de profundidade, em sedimentos formados por silte muito fino, silte médio, silte grosso, argila, areia muito fina, areia fina, grânulo. Diferenças significativas entre espécimes adultos e jovens com 3,0 mm de diâmetro do disco foram observadas por Tommasi
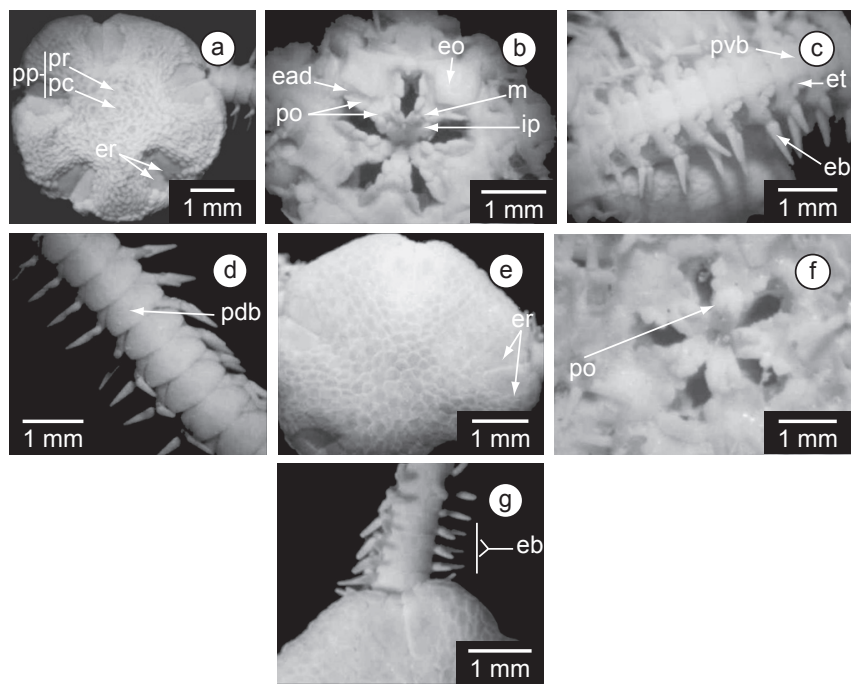

Figura 15. Amphiodia atra (Stimpson): a) Vista aboral do disco, escudos radiais (er), placas primárias $(\mathrm{pp})=$ placa central $(\mathrm{pc})$ e placas radiais $(\mathrm{pr}) ; \mathrm{b})$ Vista oral, escudo oral (eo), escudo adoral (ead), mandíbula (m), papilas orais (po) e papila infradental (ip); c) Vista oral do braço onde placa oral do braço (pvb), escamas tentaculares (et) e espinhos braquiais (eb); d) Vista aboral do braço e placa aboral do braço (pdb). Amphiodia planispina (Martens): e) Vista aboral, escudos radiais (er); f) Vista oral, papilas orais (po); e g) Vista aboral do disco e braço, espinhos do braço (eb).

Figure 15. Amphiodia atra (Stimpson): a) Aboral view, radial shield (er), primary plates $(\mathrm{pp})=$ central plate $(\mathrm{pc})$ and radial plates $(\mathrm{pr})$; b) Oral view, oral shield (eo), adoral shield (ead), jaw (m), oral papillae (po) and infradental papillae (ip); c) Oral view of the arm, oral arm plate (pvb), tentacle scale (et) and brachial spines (eb); d) Aboral arm view and aboral arm plate (pdb). Amphiodia planispina (Martens): e) Aboral view, radial shiels (er); f) Oral view, oral papillae (po); and g) Aboral view of the disc and arm, arm spines (eb). (1970b). Nos indivíduos menores as placas primárias são bem visíveis, o mesmo não ocorrendo naqueles indivíduos com mais de $5 \mathrm{~mm}$ de diâmetro de disco. Os escudos orais são tão largos quanto longos, os escudos adorais têm expansões laterais bastante acentuadas, as papilas orais no mesmo interradio estão em leve contato fechando a armação bucal. As placas ventrais dos braços são mais longas do que largas. Tommasi (1970b) observou gônadas maduras no mês de julho em exemplares da Ilha Anchieta, Ubatuba e São Sebastião, litoral de São Paulo, quando os indivíduos apresentaram o disco dilatado nos interradios ventrais e na região dorsal. Na Baía de Todos os Santos indivíduos com gônadas maduras e indivíduos com a parte superior do disco destacada, foram observados em abril e maio de 1997. Na verdade, estes dois períodos (julho na região sudeste e abril/maio, na região nordeste) compreendem estações nas quais a média pluviométrica é relativamente baixa, revelando assim provavelmente um período reprodutivo relacionado às salinidades maiores.

\section{Amphiodia planispina (Martens, 1867)}

(Figura 15e,f,g)

Material estudado: Seis espécimes coletados nas estações S4, S6 e P3.

Descrição: Disco arredondado e coberto por pequenas escamas. Com as placas primárias aparentes. Os escudos radiais são pouco mais longos do que largos, sendo o par separado apenas na região anterior por sete a quatorze escamas. Escamas da região oral do disco, pouco menores do que as aborais e com o bordo levemente denteado. Os escudos orais são losangulares. Os escudos adorais são alargados, não se tocando na região proximal. Com duas papilas orais quadrangulares de cada lado das mandíbulas, sendo que a distal é pouco maior que a proximal. Com um par de papilas infradentais. Braços com as placas aborais mais largas do que longas. As placas orais pentagonais e apresentando duas escamas tentaculares. Os três espinhos braquiais são fortemente comprimidos lateralmente. O superior é maior que os demais espinhos na região próxima ao disco, mas na direção do meio do braço, o inferior aumenta de tamanho.

Observações: Os espécimes foram coletados entre 16 e 56 m em sedimentos formados por areia média, areia grossa, areia muito grossa. Um indivíduo com gônadas maduras foi observado em maio de 1997.

3. Amphiodia riisei (Lütken, 1859)

(Figura 16a,b)

Material estudado: 14 espécimes obtidos nas estações C4, I1, I2, I4, S4, S7 e P5.

Descrição: Disco arredondado, com suaves reentrâncias interradiais e coberto por escamas bem desenvolvidas. As cinco escamas primárias e a central são subpentagonais e maiores do que as demais, mesmo nos exemplares adultos. Escudos radiais ocupando $1 / 4$ do diâmetro do disco, sendo mais largos distalmente e mais estreitos anteriormente. Estes escudos são unidos, salvo na região proximal onde podem estar intercaladas de uma a três escamas pequenas. Atrás destes escudos, podem ser observadas duas escamas quadrangulares e duas a três escamas robustas. As escamas da face oral são fortemente imbricadas e menores do que as da face aboral. Nos indivíduos jovens, as escamas da face oral podem salientar-se sobre as escamas distais da face aboral. As fendas bursais são longas e estreitas. Escudos orais muito alargados na região mediana e afilados na região distal. A madreporita é maior que os demais escudos orais. Escudos adorais curtos, alargados distalmente e unidos na região proximal. Mandíbulas curtas, estreitas e com uma forte depressão mediana. 

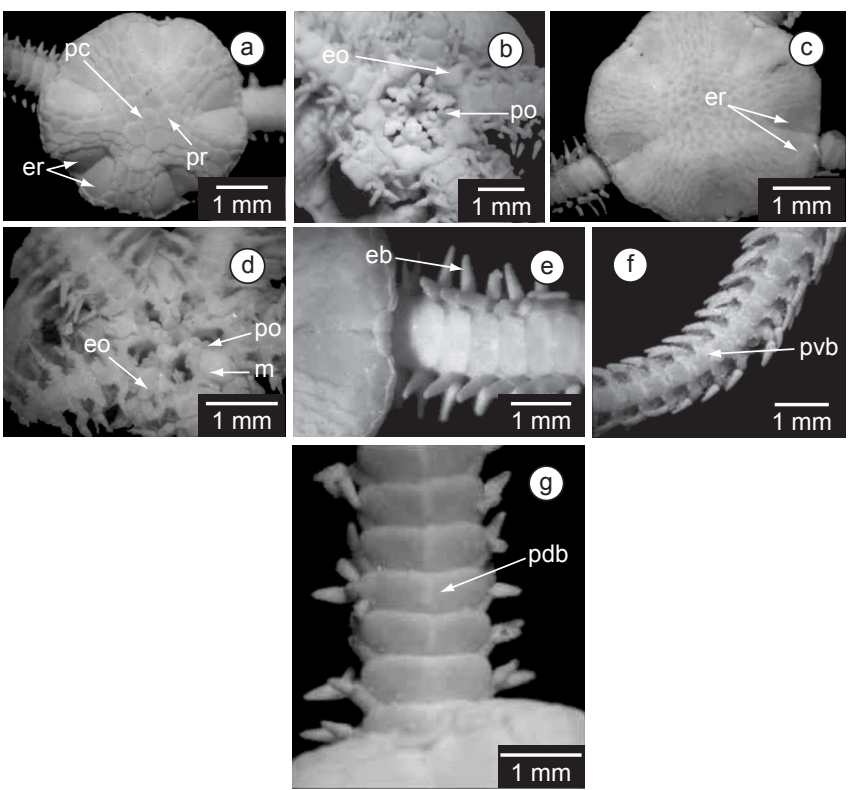

Figura 16. Amphiodia riisei (Lütken): a) Vista aboral do disco, escudos radiais (er), placa radial (pr) e placa central (pc); b) Vista oral do disco, escudo oral (eo) e papila oral (po). Amphiodia trychna (H.L. Clark): c) Vista aboral do disco e escudos radiais (er); d) Vista oral do disco e base dos braços, escudo oral (eo), madreporita (m) e papilas orais (po); e) Vista aboral do braço e espinhos (eb); f) Vista oral do braço e placas ventrais do braço (pvb); e g) Vista aboral do braço e placas aborais do braço (pdb).

Figure 16. Amphiodia riisei (Lütken): a) Aboral view of the disc and radial shield (er), radial plate (pr) and central plate (pc); b) Oral view of the disc, oral shield (eo) and oral papillae (po). Amphiodia trychna (H.L. Clark): c) Aboral view of the disc and radial shields (er); d) Oral view of the disc and base of the arm, oral shield (eo), madreporite (m) and oral papillae (po); e) Aboral view of the arm and spines (eb); f) Oral view of the arm and oral arm plates (pvb); and g) Aboral view of the arm and aboral arm plates (pdb).

Com duas papilas orais de cada lado das mandíbulas, sendo a mais externa ligeiramente maior que a mais interna. Com duas papilas infradentais estreitas no ápice das mandíbulas. Braços com o comprimento aproximado de quatro vezes o diâmetro do disco. Com duas escamas tentaculares não iguais. Placas braquiais aborais quatro vezes mais largas do que longas. Placas braquiais orais subpentagonais. Placas braquiais laterais com três espinhos rômbicos levemente comprimidos na região média distal.

Observações: A espécie foi obtida entre 1,5 e $56 \mathrm{~m}$ de profundidade, em sedimentos formados por areia muito fina, areia fina, areia média, areia grossa e argila.

4. Amphiodia trychna H.L. Clark, 1918

(Figura 16c,d,e,f,g)

Material examinado: Três espécimes coletados na estação S4.

Descrição: Disco com 4,5 a 5,0 mm de diâmetro, apresentando contorno circular e coberto por escamas imbricadas e levemente espessas. Escudos radiais pouco mais longos do que largos e unidos. Escamas da região interradial oral são menores do que as da região aboral. Escudos orais em forma de losango alongado. Escudos adorais alargados distalmente e não contíguos proximalmente. Mandíbulas curtas com uma depressão mediana. Com duas papilas orais subiguais de cada lado das mandíbulas. As papilas infradentais são retangulares. Braços quebrados nos exemplares examinados. As placas aborais são mais largas do que longas e contíguas. As placas orais são tão largas quanto longas. Com duas escamas tentaculares. Placas laterais com três espinhos braquiais subiguais comprimidos dorso ventralmente, sendo que esta compressão é mais forte no espinho superior.

Observações: Os indivíduos foram coletados a $48 \mathrm{~m}$ de profundidade em sedimentos formados por silte médio. Estes indivíduos apresentaram gônadas maduras em maio, em uma parte dorsal destacada do restante do disco. De acordo com Hendler et al. (1995), esta espécie se enterra profundamente no sedimento lamoso e com as pontas dos braços para fora recolhe alimento na forma de detritos. Esta espécie foi registrada no Brasil apenas na região sudeste (Borges 2007), assinalamos aqui o seu primeiro registro para o nordeste do Brasil.

5. Amphiodia pulchella (Lyman, 1869)

(Figura 17a,b,c)

Material estudado: 30 espécimes nas estações 18, C4, S4, S5, S7, P2, P5.

Descrição: Disco coberto por pequenas escamas, com as primárias bem evidentes, dando um aspecto delicado ao mesmo. Escudos radiais alongados, estreitos e unidos, podendo em alguns casos ser observada uma pequena escama proximal. Escamas orais interradiais semelhante às aborais, apenas um pouco menores. Escudos orais grandes, alargados na região mediana. Escudos adorais afilados anteriormente e alargados distalmente. Com duas pequenas papilas orais semelhantes de cada lado das mandíbulas. Papilas infradentais robustas. Braços alongados e finos; com uma pequena escama tentacular. Placas aborais mais largas do que longas. Placas orais pentagonais. Com três espinhos braquiais, sendo o mediano mais robusto e achatado no sentido aboral/oral, com dentículos.

Observações: Os exemplares foram obtidos entre 7,8 e $56 \mathrm{~m}$ de profundidade, em sedimentos formados por areia muito fina, areia média, areia grossa e areia muito grossa. A maior parte dos indivíduos foi coletada com draga na estação S4 em maio de 1997. Entre os espécimes de A. pulchella estudados nesta estação, aproximadamente metade estavam com as gônadas maduras e a outra metade com a parte superior do disco destacada. Este comportamento é bastante comum em exemplares da família Amphiuridae durante o período reprodutivo, pois quando a parte superior do disco é destacada carrega a maior parte das gônadas. De acordo com Hendler et al. (1995), os exemplares desta espécie podem ser encontrados em densidades elevadas em sedimentos pobremente oxigenados e cobertos por algas assim como associadas a algas, estendendo dois ou três braços para a coleta de alimento. A. pulchella foi encontrada no conteúdo estomacal da estrela Luidia senegalensis e do peixe Serranus subligarius (Hendler et al. 1995).

6. Amphipholis januarii Ljungman, 1867

(Figura 18a,b,c,d)

Material estudado: 41 espécimes coletados nas estações $\mathrm{C} 4$, S5, P2, P3, P5.

Descrição: Disco com reentrâncias interradiais, coberto por escamas pequenas e imbricadas. As escamas primárias são mais visíveis nos menores exemplares. Escudos radiais muito mais longos do que largos, separados apenas na região proximal por até quatro escamas estreitas. Escamas da face oral do disco menores do que as da face aboral. Escudos orais losangulares. Escudos adorais não contíguos na região proximal. Com duas papilas orais em cada lado das mandíbulas, das quais a posterior é bem mais alongada do que anterior. Papilas infradentais quase 

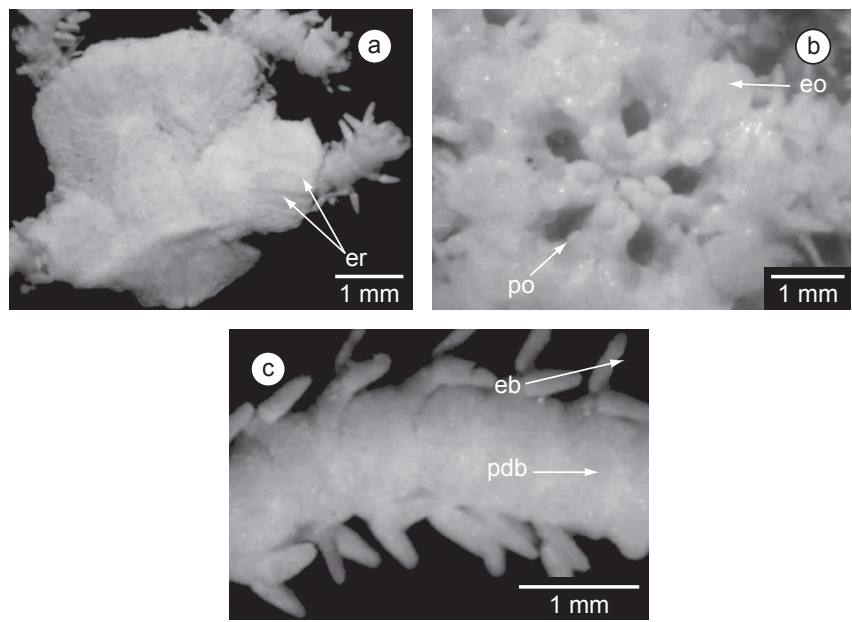

Figura 17. Amphiodia pulchella (Lyman): a)Vista aboral do disco e escudos radiais (er); b) Vista da armação oral, escudo oral (eo) e papilas orais (po); e c) Vista aboral do braço, placas aborais do braço (pdb) e espinhos braquiais (eb).

Figure 17. Amphiodia pulchella (Lyman): a) Aboral view of the disc and radial shields (er); b) View of the oral frame, oral shield (eo) and oral papillae (po); and c) Aboral view of the arm, Aboral arm plates (pdb) and brachial spines $(\mathrm{eb})$.

retangulares. Braços longos com as placas orais pentagonais. Com duas escamas tentaculares. Placas aborais mais largas do que longas. Com três a quatro espinhos braquiais alongados principalmente na região proximal. $\mathrm{O}$ espinho mediano possui dentículos na sua extremidade.

Observações: Os exemplares foram coletados entre 7,8 e $39 \mathrm{~m}$ de profundidade, em sedimentos formados por areia muito fina, areia fina, areia média, areia muito grossa. Indivíduos com gônadas maduras assim como aqueles sem a parte dorsal do disco foram registrados em abril e maio de 1997.

7. Amphipholis squamata (Delle Chiaje, 1928)

(Figura 18e,f,g)

Material estudado: 24 espécimes coletados nas estações C1, I2, I4, I5, S7 e P2.

Descrição: Disco arredondado coberto por escamas imbricadas, sendo as escamas central e primárias visíveis. Escudos radiais pouco mais longos do que largos, unidos salvo na porção proximal onde está intercalada uma pequena escama. Escamas da região interradial oral do disco, fortemente imbricadas. Escudos orais afilados anteriormente. Escudos adorais alargados distalmente. Papila oral distal alongada e maior do que a papila oral proximal. Papilas infradentais irregulares. Braços curtos e com aproximadamente três vezes o diâmetro do disco. Placas orais dos braços pentagonais. Com duas escamas tentaculares principalmente nos adultos. Com três espinhos braquiais curtos e com dentículos.

Observações: Os espécimes foram coletados em profundidades entre oito e $39 \mathrm{~m}$ e em sedimentos formados por silte muito fino, silte médio, silte grosso, areia fina, areia muito grossa e grânulo.

8. Amphipholis subtilis (Ljungman, 1867)

(Figura 18h,i)

Material estudado: 32 espécimes coletados nas estações 5, N5, M2, M4, C4, I4, S1, S2, S3, S5.
Descrição: Disco pentagonal coberto por escamas pequenas e imbricadas e de aspecto delicado. Escudos radiais longos e estreitos na maioria dos exemplares, unidos em toda a sua extensão. Escamas da região oral interradial do disco cobertas por escamas menores do que as da região aboral. Fendas bursais alongadas. Escudos orais com a região distal curva e a proximal mais afilada. Madreporito maior que os demais escudos orais. Escudos adorais estreitos. Com duas papilas orais, a distal maior que a proximal. Braços bastante alongados, estreitos, dando a impressão de serem extremamente frágeis. Placas aborais dos braços quase tão longas quanto largas. Placas orais dos braços semi-pentagonais. Com três espinhos braquiais afilados. Com duas escamas tentaculares. Em álcool sua coloração permanece laranja ou avermelhada.

Observações: Os exemplares foram obtidos entre 7 e $62 \mathrm{~m}$ de profundidade em sedimentos formados por silte médio, areia fina, areia média e argila. Tommasi (1970b) observou uma grande quantidade de indivíduos, sem a parte dorsal do disco, de julho de 1961 a fevereiro de 1962 na região de Ubatuba e São Sebastião no estado de São Paulo, observando que este comportamento possa resultar em um meio mais eficiente para a liberação dos gametas. Comportamento semelhante foi observado nos espécimes coletados na Baía de Todos os Santos, onde espécimes sem a parte dorsal do disco foram coletados em julho de 1996 e em abril e maio de 1997.

9. Ophiostigma isocanthum (Say, 1825)

(Figura 19a,b,c)

Material estudado: 174 espécimes obtidos nas estações I1, I2, I5, S4, S5, S7, P1, P2 e P3.

Descrição: Disco arredondado coberto por escamas nas regiões aboral e oral, assim como por numerosos grânulos alongados e estreitos que podem cobrir até os escudos radiais. Escudos radiais curtos e unidos. Região interradial oral semelhante à aboral. Escudos orais mais largos do que longos, afilados anteriormente. Escudos adorais levemente inflados e contíguos anteriormente. Com duas papilas orais em cada lado das mandíbulas, sendo que a distal é mais do que o dobro do tamanho da proximal, tornando os espaços entre as mandíbulas fechados. Braços longos. As placas aborais dos braços são mais largas do que longas, com o bordo distal levemente arredondado. Placas braquiais orais sub-pentagonais. Placas braquiais laterais cobertas por granulação fina, com três espinhos braquiais rômbicos e duas escamas tentaculares.

Observações: Os espécimes foram obtidos entre 1,5 e $56 \mathrm{~m}$ de profundidade em sedimentos formados por silte muito fino, silte grosso, areia muito fina, areia média, areia grossa, areia muito grossa e grânulo.

Nas coletas de março e abril de 1997, 15\% dos indivíduos apresentavam gônadas maduras e $24 \%$ estavam sem a região aboral do disco. Neste período também foi registrado que $0,5 \%$ de partes aborais do disco destacadas estavam portando gônadas maduras. Em abril de 1997 também foi observado que: 60\% dos indivíduos estavam no início da fase de regeneração da parte aboral do disco, 13,4\% em fase final de regeneração e $24 \%$ dos espécimes apresentaram a região aboral recém regenerada, mas ainda não totalmente desenvolvida.

10. Ophiocnida loveni (Ljungman, 1866)

(Figura 19d,e)

Material estudado: 10 espécimes coletados nas estações C3, I1, I4, P5.

Descrição: Disco circular coberto por escamas grandes e irregulares, recobertas por fina granulação. Escamas da região distal do 

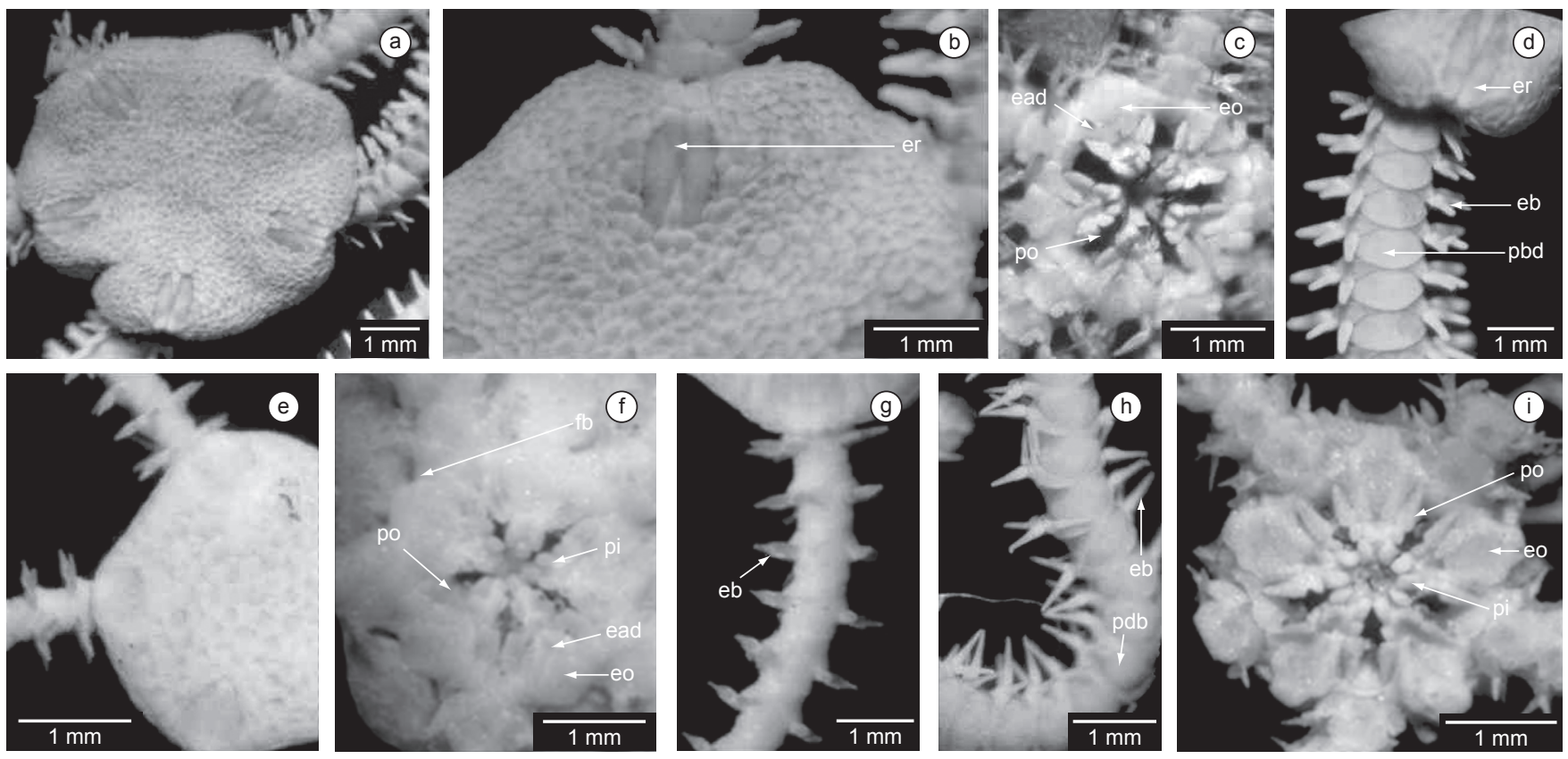

Figura 18. Amphipholis januarii (Ljungman): a) Vista aboral do disco; b) Detalhe das escamas aborais do disco e dos escudos radiais (er); c) Vista da armação oral, escudos orais (eo), escudos adorais (ead) e papilas orais (po); d) Vista dos escudos radiais (er), placas aborais dos braços (pdb) e espinhos (eb). Amphipholis squamata (Delle Chiaje): e) Vista aboral do disco; f) Vista oral do disco, fendas bursais (fb), escudos orais (eo), escudos adorais (ead), papilas orais (po) e papilas infradentais (pi); g) Vista aboral do braço e espinhos (eb). Amphipholis subtilis (Ljungman): h) Placas dorsais dos braços (pdb) e espinhos (eb); e i) Vista da armação oral, escudos orais (eo), papilas orais (po) e papilas infradentais (pi).

Figure 18. Amphipholis januarii (Ljungman): a) Aboral view of the disc; b) Detail of the aboral scales of the disc and radial shields (er); c) View of the oral frame, oral shiels (eo), adoral shields (ead), and oral papillae (po); d) View of the radial shields (er), aboral arm plates (pdb) and spines (eb). Amphipholis squamata (DelleChiaje): e) Aboral view of the disc; f) View oral of the disc, bursal slit (fb), oral shield (eo), adoral shield (ead), oral papillae (po) and infradental papillae (pi); g) Aboral view of the arm and spines (eb); Amphipholis subtilis (Ljungman): h) Aboral arm plates (pdb) and spines (eb); and i) View of the oral frame, oral shield (eo), oral papillae (po) and infradental papillae (pi).
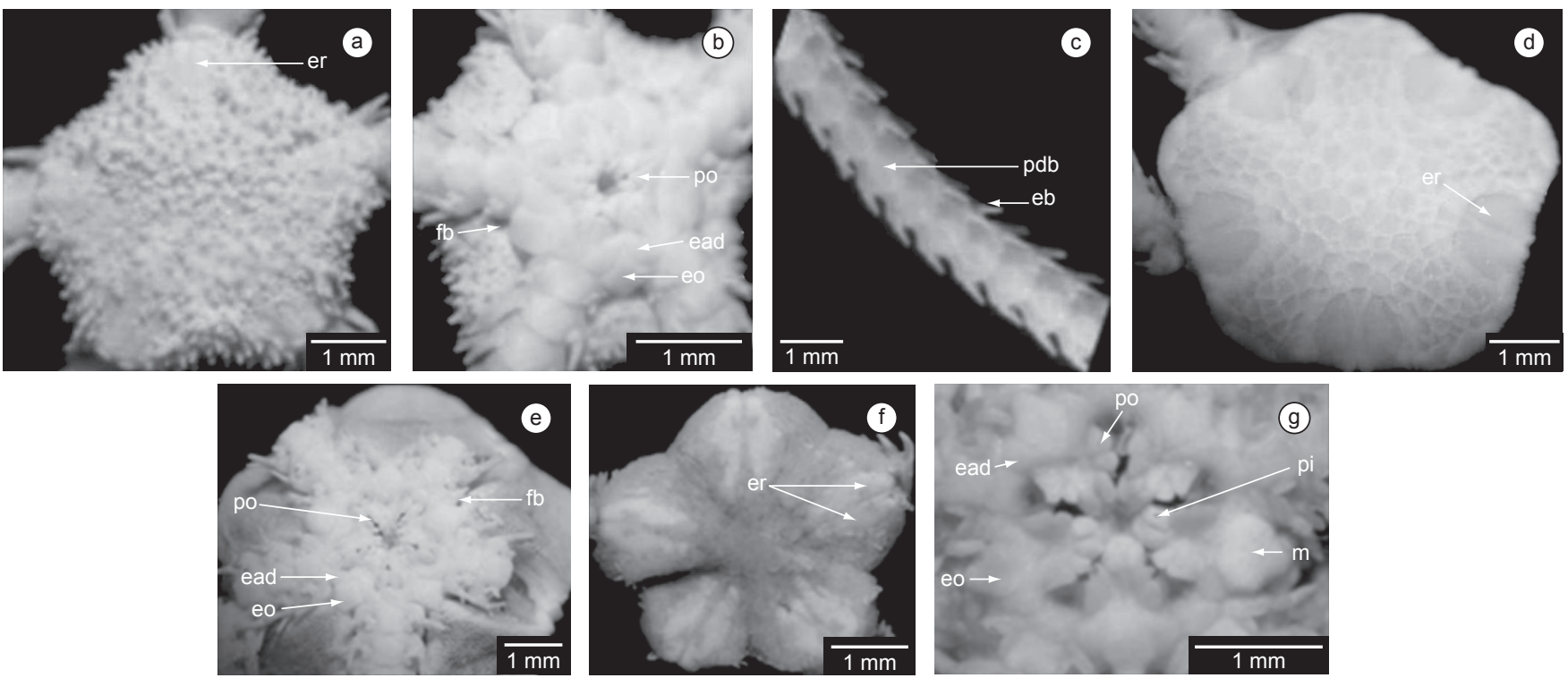

Figura 19. Ophiostigma isocanthum (Say): a) Vista aboral do disco e escudos radiais (er); b) Vista oral do disco onde fendas bursais (fb), escudo oral (eo), escudo adoral (ead) e papilas orais (po); c) Vista das placas aborais do braço (pdb) e espinhos (eb). Ophiocnida loveni (Ljungman): d) Vista aboral do disco e escudos radiais (er); e) Vista oral do disco onde fendas bursais (fb), escudo oral (eo), escudo adoral (ead) e papilas orais (po). Ophiophragmus luetkeni (Ljungman): f) Vista aboral do disco e escudos radiais (er); e g) Vista da armação oral, escudo oral (eo), madreporita (m), escudo adoral (ead), papilas orais (po) e papila infradental (pi).

Figure 19. Ophiostigma isocanthum (Say): a) aboral view of the disc and radial shields (er); b) Oral view of the disc were bursal slit (fb), oral shield (eo), adoral shield (ead) and oral papillae (po); c) View of the aboral arm plates (pdb) and spines (eb); Ophiocnida loveni (Ljungman): d) Aboral view of the disc and radial shields (er); e) Oral view of the disc were bursal slit (fb), oral shield (eo), adoral shield (ead) and oral papillae (po); Ophiophragmus luetkeni (Ljungman): f) Aboral view of the disc and radial shields (er); and g) View of the oral frame, oral shield (eo), madreporite (m), adoral shield (ead), oral papillae (po), and infradental papillae (pi). 
disco com tubérculos. Os escudos radiais triangulares, pouco mais longos do que largos, unidos, salvo na região proximal onde estão separados por uma ou duas escamas. A região oral interradial do disco é coberta por grânulos espiniformes. Os escudos orais são losangulares. Os escudos adorais apresentam uma expansão distal e são contíguos na região proximal. Mandíbulas curtas e com uma depressão mediana. Com duas, algumas vezes três, papilas orais de cada lado das mandíbulas, a distal pouco maior que a proximal. As papilas orais das mandíbulas vizinhas estão posicionadas na maioria das vezes muito próximas fechando o sulco oral. Braços afilados e não muito longos. Placas aborais mais largas do que longas. Placas orais pentagonais com uma reentrância no bordo distal. Placas laterais com três a quatro espinhos braquiais. Com duas escamas tentaculares.

Observações: Os exemplares foram coletados em profundidades que variaram entre 7 e $48 \mathrm{~m}$, em sedimentos formados por silte médio areia muito fina e areia fina. Foram observadas gônadas maduras em um indivíduo coletado em abril de 1997.

11. Ophiophragmus luetkeni (Ljungman, 1871) (Figura 19f,g)

Material estudado: Um espécime coletado na estação I2.

Descrição: Disco arredondado ou pentagonal, com reentrâncias radiais, coberto por escamas pequenas, imbricadas e irregulares, com a escama central bem visível e pouco maior que as demais. Escudos radiais desenvolvidos, quase triangulares, pouco mais longos do que largos, sendo a maior largura na região distal do escudo. O par normalmente está separado anteriormente por uma escama triangular. Atrás dos escudos radiais encontram-se duas escamas retangulares com dois a quatro espinhos aderidos lateralmente. Espinhos marginais afilados, ao redor do disco. Em cada interradio entre os pares de escudos radiais são observados mais de 22 espinhos. Escamas da região interradial oral bem menores e imbricadas do que as da região aboral. Fendas bursais longas e com uma escama longa nas suas bordas. Escudos orais quase losangulares. Madreporita maior que os demais escudos e com um poro na região distal. Escudos adorais alargados distalmente e não contíguos na região proximal. Mandíbulas curtas com uma forte depressão distal. Com duas papilas orais, pequenas e normalmente de coloração escura, em cada lado das mandíbulas, sendo a distal pouco maior que a proximal. Papilas infradentais retangulares, separadas no ápice das mandíbulas. Braços longos e afilados. Placas aborais quase quatro vezes mais largas do que longas com uma leve reentrância no bordo distal. Placas orais quadrangulares, mesmo em álcool, de uma tonalidade escura. Com duas escamas tentaculares, uma aderida à placa oral e outra à placa lateral. Placas laterais estreitas com três espinhos braquiais ligeiramente afilados.

Observações: Os espécimes foram coletados a profundidade de 1,5 m em sedimento classificado como silte grosso.

\section{Ophionephthys limicola Lütken, 1869}

Material estudado: Três espécimes obtidos na estação M3.

Descrição: Disco arredondado com fortes reentrâncias interradiais. $\mathrm{O}$ disco possui escamas apenas nas regiões distais dos escudos radiais e dispostas em série próximas à margem do disco. Escudos radiais são longos, estreitos e separados. Região oral interradial sem escamas. Escudos orais alongados com a região mediana mais larga. A madreporita é maior que os demais escudos orais. Escudos adorais não contíguos e com a extremidade distal alargada. Mandíbulas elevadas anteriormente e com quatro a cinco papilas orais de cada lado. Papilas infradentais quadrangulares no ápice das mandíbulas. Placas aborais dos braços, pouco mais largas do que longas. Placas orais quadrangulares. Braços longos com até cinco espinhos braquiais afilados, e com uma pequena escama tentacular.

Observações: Os exemplares foram coletados a $3 \mathrm{~m}$ de profundidade em sedimento formado por areia média. De acordo com Hendler et al. (1995), esta espécie é detritívora seletiva e utiliza seus braços longos para coletar partículas da superfície do sedimento.

\section{Amphiura kinbergi (Ljungman, 1871)}

(Figura 20a,b,c)

Material estudado: Dois espécimes na estação I1.

Descrição: Disco arredondado, com reentrâncias interradiais e coberto por escamas pequenas e esparsas, estando estas mais concentradas ao redor dos escudos radiais. Escudos radiais mais longos do que largos, divergentes entre si. Região oral interradial do disco sem escamas. Escudos orais alargados. Escudos adorais não contíguos na região proximal e alargado na distal. Papila infradental robusta. Com duas papilas orais de cada lado das mandíbulas separadas por um espaço (diástema), sendo a proximal afilada e a distal pouco alargada. Braços longos e delicados com duas escamas tentaculares pequenas. Placas orais sub-pentagonais. Com seis a sete espinhos braquiais com dentículos, sendo no inferior onde estes dentículos são maiores e mais visíveis.

Observações: Encontrado a profundidade de $24 \mathrm{~m}$ em sedimento formado por areia muito fina.

14. Amphiura palmeri Lyman, 1882

(Figura 20d,e)

Material estudado: Sete exemplares nas estações S5 e P2.

Descrição: Disco arredondado com leves reentrâncias radiais e fortes reentrâncias interradiais, coberto aboralmente por escamas

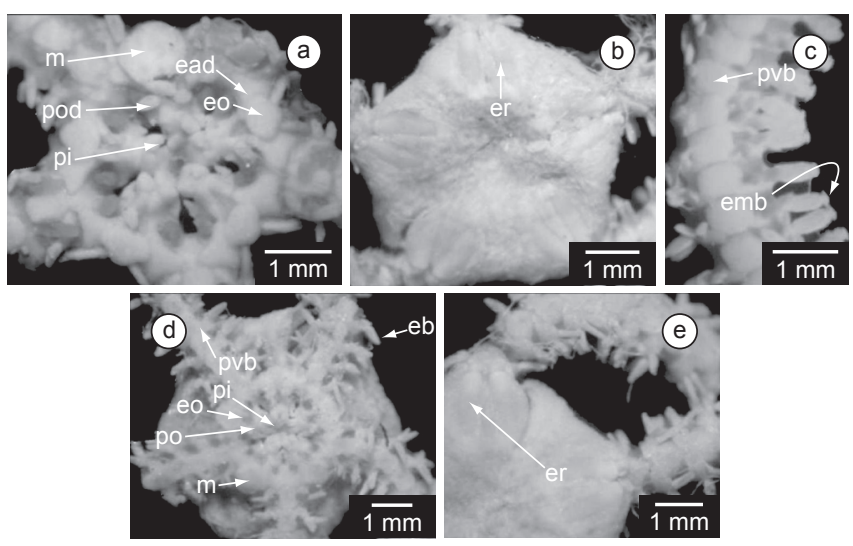

Figura 20. Amphiura kinbergi (Ljungman): a) Vista da armação oral, madreporita (m), escudo oral (eo), escudo adoral (ead), papila oral (po) e papila infradental (pi); b) Vista aboral do disco e escudos radiais (er); c) Vista das placas orais dos braços (pvb) e espinhos medianos (emb). Amphiura palmeri (Lyman): f) Vista oral do disco e braços, placa oral dos braços (pvb), madreporita (m), escudo oral (eo), papilas orais (po) e papilas infradentais (pi); g) Detalhe da superfície aboral do disco com escudos radiais (er) e braços.

Figure 20. Amphiura kinbergi (Ljungman): a) View of the frame oral, madreporite (m), oral shield (eo), adoral shield (ead), oral papillae (po) and infradental papillae (pi); b) Aboral view of the disc and radial shields (er); c) View of the oral arm plates (pvb) and middle spines (emb). Amphiura palmeri (Lyman): f) Oral view of the disc and arms, oral arm plate (pvb), madreporite $(\mathrm{m})$, oral shield (eo), oral papillae (po) and infradental papillae (pi); and g) Detail of the aboral surface of the disc with radial shields (er) and arms. 
pequenas e levemente imbricadas. Escudos radiais três vezes mais longos do que largos, separados por aproximadamente doze escamas. Região oral do disco coberta por escamas pequenas e fortemente imbricadas que ultrapassaram o âmbitus e por escamas esparsas na região interna. Escudos orais pequenos sublosangulares. A madreporita é duas vezes e meio maior que os demais escudos e com a região distal elevada. Escudos adorais grandes, contíguos anteriormente e alargados distalmente. Mandíbulas curtas e elevadas na região proximal. Com duas pequenas papilas infradentais no ápice das mandíbulas. Com uma pequena papila oral proximal levemente afilada na região interna de ambos os lados das mandíbulas. Esta pequena papila está separada por um espaço (diástema) da papila oral distal, posicionada verticalmente, na região entre a mandíbula e o escudo adoral. Braços longos. Placas aborais dos braços quase ovais, mais largas do que longas. Placas laterais estreitas com seis a sete espinhos braquiais levemente comprimidos, que aumentam de tamanho do aboral para o oral, e com um dente terminal. Placas orais sub-pentagonais, com duas escamas tentaculares, sendo a interna maior que a externa.

Observações: Encontrada entre 12 e $20 \mathrm{~m}$ de profundidade, em sedimentos formados por areia muito fina e areia média. Um indivíduo portando gônadas maduras foi observado em abril de 1997.

Família Ophiothrichidae Ljungman, 1867

1. Ophiothrix angulata (Say, 1825)

(Figura 21a,b,c)

Material estudado: 33 exemplares coletados nas estações: M3, I1, S7 e P2.

Descrição: Disco arredondado com reentrâncias radiais. As escamas do disco são pequenas e cobertas por espinhos delicados,
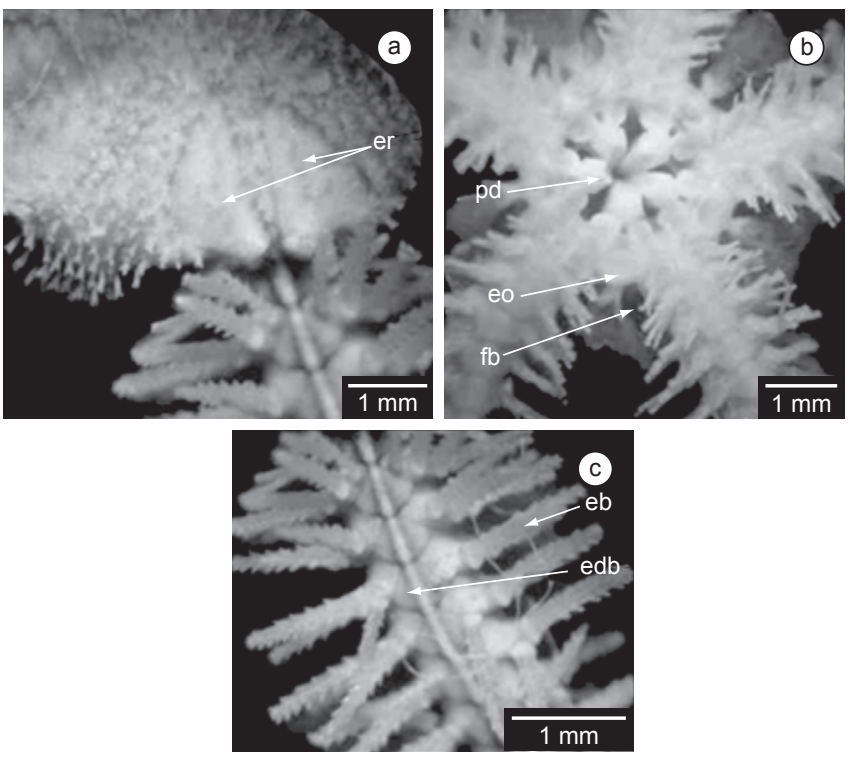

Figura 21. Ophiothrix angulata (Say): a) Detalhe da superfície aboral, escudos radiais (er) e braços; b) Vista oral, fendas bursais (fb), escudos orais (eo) e papilas dentais (pd); e c) Detalhe das placas aborais do braço (pdb) e espinhos (eb).

Figure 21. Ophiothrix angulata (Say): a) Detail of the aboral surface, radial shields (er) and arms; b) Oral view, bursal slit (fb), oral shields (eo) and dental papillae (pd); and c) Detail of the aboral plates of the arm (pdb) and spines (eb). hialinos, curtos com as extremidades divididas em duas ou três pontas. Entre estes espinhos podem existir alguns espinhos mais longos e finos, dispersos sobre o disco ou entre os escudos radiais. Escudos radiais com tamanho aproximado de 1/4 do diâmetro do disco, mais longos do que largos e separados por escamas alongadas. Sobre os escudos radiais muitas vezes são encontrados espinhos curtos com pontas bífidas e trífidas. A região oral interradial é coberta por escamas e espinhos semelhantes aos da região aboral, pelo menos até a metade distal em muitos indivíduos, ficando o restante sem escamas ou espinhos. Escudos orais alargados. Escudos adorais alargados distalmente. Sem papilas orais e com um feixe de papilas dentais no ápice das mandíbulas. Braços não muito longos. Placas aborais dos braços tão largas quanto longas e com a extremidade distal fortemente arredondada. Placas orais com seis a oito lados. Com uma pequena escama tentacular alongada. Espinhos braquiais em número de oito a onze. Estes espinhos são hialinos, sendo que aqueles mais próximos ao disco são fortemente denteados. São conhecidos diversos padrões de coloração nesta espécie, podendo a mesma variar do rosa pálido quase branco ao violeta próximo ao negro, algumas vezes apresentando uma lista preta ou branca na superfície dos braços, ou outros tipos de padrões de coloração.

Observações: $O$. angulata foi coletada entre 12 e $23 \mathrm{~m}$ de profundidade em sedimentos formados por silte médio, areia muito fina, areia média e areia muito grossa. Gônadas maduras foram observadas em abril em grande parte do exemplares da estação P2.

\section{Discussão}

Comparando os resultados de distribuição dos equinodermos na Baía de Todos os Santos com aqueles encontrados em outras baías brasileiras, verificou-se que Amphiodia atra também foi à espécie dominante na baía de Camamu (BA), onde foi coletada junto com os ofiuróides Amphioplus camamuensis e Amphiodia pulchella e o equinóide Agassizia excentrica (Manso 2004). Na Baía da Ribeira, em Angra dos Reis (RJ), na área dos Sacos de Piraquara de Fora e Piraquara de Dentro, Manso \& Absalão (1988) encontraram, durante a fase pré-operacional da usina nuclear Angra I, que Amphiodia atra (naquele trabalho como Micropholis atra) ocorreu em $80 \%$ das estações onde foram registrados ofiuróides, em sedimentos classificados como: lama, lama arenosa, areia lamosa e areia. Na Baía da Ribeira, assim como na Baía de Todos os Santos, os ofiuróides Amphipholis subtilis (naquele trabalho como Micropholis subtilis) e Amphiodia riisei (naquele trabalho como Diamphiodia riisei) foram os ofiuróides mais freqüentes, ocorrendo em boa parte das estações. Uma das diferenças observadas entre a Baía de Todos os Santos e a Baía da Ribeira em relação à distribuição dos Ophiuroidea, foi quanto à freqüência de ocorrência da espécie Hemipholis elongata. Na Baía da Ribeira, $H$. elongata foi bem representada ocorrendo em 59,6\% das estações, sendo a segunda espécie mais freqüente, enquanto que na Baía de Todos os Santos sua freqüência foi de apenas $11 \%$. A explicação deste resultado pode estar na diferença dos aparelhos utilizados nas amostragens, ou ainda por esta espécie preferir ambientes eutrofizados ou poluídos (Hendler et al., 1995), provavelmente não sendo ainda o caso da Baía de Todos os Santos. Hemipholis elongata foi também registrada na Baía de Aratu, localizada ao fundo da Baía de Todos os Santos, junto às espécies Amphiodia atra e Amphipholis subtilis. Esta pequena baía se encontra atualmente com um elevado nível de poluição.

Os registros de Ophiuroidea Amphiodia trychna e Ophiactis brasiliensis, coletados na Baía de Todos os Santos constituem os primeiros registros destas espécies no nordeste do Brasil. 
Entre as espécies de Echinoidea, Cassidulus infidus, coletada nos sedimentos formados por areia média da Baía de Todos os Santos, amplia o conhecimento desta espécie, cuja descrição e único exemplar conhecido era do holótipo, amostrado na plataforma continental adjacente ao Estado da Bahia.

O asteróide Oreaster reticulatus aparentemente é um dos asteróides mais conhecidos do litoral baiano, devido ao seu uso em ornamentação e religião. De acordo com Hendler et al. (1995), esta é uma espécie vulnerável à exploração humana e é atualmente considerada rara em áreas onde antes era comum.

Nas estações das áreas P, S e I (Figura 1), foi registrada a maior abundância e diversidade de equinodermos, fato que talvez possa ser explicado pelo tipo de fundo encontrado nessas áreas, formado por um maior conteúdo da fração areia; por estas estações estarem posicionadas mais próximas à entrada da baía, onde a circulação das correntes é mais eficiente; ou mais afastadas da desembocadura de rios onde estão localizados os maiores problemas referentes à poluição, assim como a menor salinidade.

O estudo dos equinodermos da Baía de Todos os Santos e da Baía de Aratu foi importante, pois até este momento muito pouco se conhecia sobre a distribuição e ocorrência das espécies no litoral do Estado da Bahia. O conhecimento das espécies de equinodermos das baías estudadas poderá servir de base para futuros monitoramentos sobre o impacto das atividades humanas no entorno destas baías, e sua influência na distribuição destes animais, assim como em outros que dependam deste ambiente, contribuindo, desta forma, para que ações sejam implementadas visando à conservação deste rico ecossistema.

\section{Agradecimentos}

Ao Fundo Mundial para a Natureza (WWF), através do Programa Natureza e Sociedade (Processo CSR 085-97), pelo financiamento do Projeto "Geoecologia das comunidades bentônicas infralitorais da Baía de Todos os Santos, BA, Brasil: diversidade biótica e sedimentológica". Ao Serviço de Sinalização Náutica do Leste (SINEST-BA), Base Naval de Aratu - Marinha do Brasil, pela utilização da embarcação Itacaré e pelo apoio "em terra" durante os trabalhos de coleta em 1996. À Capitania dos Portos de Salvador, à Estação de Desmagnetização da Marinha (Itaparica) e ao TEMADRE/ PETROBRAS (Madre de Deus) pelo apoio "em terra" durante os trabalhos de coleta em 1997. Ao PICDT-CAPES/UFBA pela concessão de uma bolsa de doutorado à segunda autora. Ao PIBIC/UFBA, pela concessão de duas bolsas de iniciação científica. Aos Profs. Eduardo Mendes e Miguel Accioly (Dep. Botânica - Instituto de Biologia/UFBA) pela participação no Projeto MAREMBA. Ao Prof. Dr. José Maria Landim Dominguez (Geologia/UFBA) pelo apoio ao trabalho de campo, utilização do Laboratório de Estudos Costeiros (Instituto de Geociências da UFBA) e sugestões. Ao Prof. Dr. Dieter Muehe (Geografia/UFRJ) pela orientação do trabalho de tese da segunda autora e oportunidade de realização da pesquisa. A todas as pessoas que participaram dos trabalhos de campo em 1996 e em 1997. Aos referis anônimos pelas correções e sugestões apresentadas ao texto.

\section{Referências Bibliográficas}

ALBUQUERQUE, M.N. \& GUILLE, A. 1991. Ophiuroidea (Echinodermata) ao largo do Brasil: Banco dos Abrolhos, Cadeia submarina VitóriaTrindade e Plataforma continental adjacente. Bol. Mus. Nac., N. S., Zool. 353: 1-29.

ALLAIN, J.Y. 1978. Déformations du test chez l'oursin Lytechinus variegates (Lamarck) (Echinoidea) de la Baie de Carthagène. Caldasia 12:365-375.
ALVES, O.F.S. \& CERQUEIRA, W.R.P. 2000. Echinodermata das praias de Salvador (Bahia, Brasil). Rev. Bras. Zool. 17(2): 543-553.

ALVES, O.F.S, MANSO, C.L.C., ABSALÃO, R.S. \& PAIVA, P.C. 2006. Geoecology of Sublittoral Benthic Communities in Todos os Santos Bay (Bahia, Brazil): Biotic and Sedimentological Diversity. J. Coast. Res. SI 39:1152-1155.

BORGES, M. \& AMARAL, A.C.Z. 2007. Ophiuroidea (Echinodermata): quatro novas ocorrências para o Brasil. Rev. Bras. Zool. 24: 855-864.

BORGES, M., MONTEIRO, A.M.G. \& AMARAL, A.C.Z. 2002 Taxonomy of Ophiuroidea (Echinodermata) from the continental shelf and slope of the Southern and Southeastern Brazilian Coast. Biota Neotrop. 2(2):1-69. http://www.biotaneotropica.org.br/v2n2/pt/ abstract?article+BN02302022002 (último acesso em 05/07/2007).

BORGES, M., MONTEIRO, A.M.G. \& AMARAL, A.C.Z. 2006. A new species of Ophiomisidium (ECHINODERMATA: OPHIUROIDEA) from de continental shelf and slope off southern Brazil. J. Mar. Biol. Ass. U. K. (86): 1449-1454.

COTEUR, G., GOSSELIN, P., WANTIER, P., CHAMBOST-MANCIET, Y., DANIS B., PERNET P. WARNAU, M. \& DUBOIS, P. H. 2003. Echinoderms as bioindicators, bioassays, and impact assessment tools of sediment-associated metals and pcbs in the North Sea. Arch. Environ. Contam. Toxicol. 45:190-202.

D.H.N. 1984. Carta Náutica 1110. 2a edição, Diretoria de Hidrografia e Navegação, Marinha, Brasil.

FOLK, R.L. 1968. Petrology of sedimentary rocks. The University of Texas. Texas. p.69.

GERMEN/UFBA - NIMA, 1997. BTS: diagnóstico sócio-ambiental e subsídios para a gestão. Edições Germen, Salvador. p.244.

HENDLER, G., MILLER; J.E., PAWSON, D.L. \& KIER, P.M. 1995. Sea stars, sea urchins, and alliens: echinoderms of Florida and the Caribbean. Washington, D. C., Smithsonian Institution Press. Washington.

LESSA, G.C., BITTENCOURT, A.C.S.P., BRICHTA, A. \& DOMINGUEZ, J.M.L. 2000. A reevaluation of the Late Quaternary sedimentation in Todos os Santos Bay (BA), Brazil. An. Acad. Bras. Ci. 72 (4):573-590.

LESSA, G.C., DOMINGUEZ, J.M.L., BITTENCOURT, A.C.S.P. \& BRICHTA, A. 2001. The tides and tidal circulation of Todos os Santos Bay, Northeast Brazil: a general characterization. An. Acad. Bras. Ci. 73(2):245-261

LESSIUS, H.A. 2005. Echinoids of the Pacific Waters of Panama: Status of knowledge and new records echinoids of the Pacific waters of Panama. Rev. Biol. Trop. 53:147-170.

MACEDO, M.H.F. 1977. Estudo Sedimentológico da Baía de Todos os Santos. Salvador. Dissertação de Mestrado, Universidade Federal da Bahia, Salvador.

MAGALHÃES, W.F., MARTINS, L.R. \& ALVES, O.F.S. 2005.Inventário dos Echinodermata do Estado da Bahia. Braz. J. Aquat. Sci. Technol. 9(1):61-65.

MANSO, C.L.C. 1988a. Uma nova espécie de Ophiactis (Echinodermata: Stelleroidea) da Costa Sudeste do Brasil. Rev. Bras. Biol. = Braz. J. Biol 48(2):375-379.

MANSO, C.L.C. 1988b. Ofiuróides da Plataforma Continental Brasileira. Parte I: Rio de Janeiro. (ECHINODERMATA: OPHIUROIDEA). Rev. Bras. Biol. = Braz. J. Biol. 48(4):845-850.

MANSO, C.L.C. 1988c. Sobre a ocorrência de Ophionema intricata Lütken, 1869 e Ophiophragmus brachyatis H.L.Clark, 1915 no Brasil (Echinodermata, Ophiuroidea, Amphiuridae) Rev. Bras. Biol. = Braz. J. Biol 48(4):965- 968.

MANSO, C.L.C. 1989. Os Echinodermata da Plataforma Continental Interna entre Cabo Frio e Saquarema, Rio de Janeiro, Brasil. Rev. Bras. Biol. = Braz. J. Biol. 49 (2): 355- 359.

MANSO, C.L.C. 1991. Ophiuroidea (Echinodermata) da região sul-sudeste do Brasil, coletados durante as "Operações Sueste do N/Oc. Almirante Saldanha”. Dissertação de Mestrado, Universidade Federal do Paraná, Curitiba. 
MANSO, C.L.C. 1993. Ofiuróides da Plataforma Brasileira. Parte II: Norte do Estado do Rio de Janeiro, Estado do Espírito Santo, Sul do Estado da Bahia e Bancos Royal Charlott, Hotspur e Davis (Echinodermata: Ophiuroidea). Rev. Bras. Biol. = Braz. J. Biol. 53(2):189-195.

MANSO, C.L.C. 2004. Os Echinodermata da bacia de Camamu, Bahia, Brasil. Rev. Biol. Gen. Exper. 5(1):19-25.

MANSO, C.L.C. 2007. Holosalenia bahiensis, um novo equinóide (Echinodermata) do Albiano da Bacia de Camamu, Brasil. Rev. Bras. Paleontol. 10(1):27-34.

MANSO, C.L.C \& ABSALÃO, R.S. 1988. Ophiuroidea: situação préoperacional nos sacos de Piraquara, região sob influência da descarga da central nuclear Almirante Álvaro Alberto (CNAA). Rev. Bras. Biol. = Braz. J. Biol. 48(1):75-82.

MANSO, C.L.C. \& FARIAS, M.C.V. 1999. Ocorrência de ofiuróides no conteúdo gastrointestinal de "baiacu" (Sphoeroides testudineus (Linnaeus, 1758) (Teleostei: Tetraodontidae) no estuário do Rio Sergipe (Sergipe). Rev. Nordest. Zool. 2(1):35-37.

MARKOV, A.V. \& SOLOVJEV, A.N. 2001. Echinoid of the family Paleopneustidae (Echinoidea, Spatangoida): Morphology, taxonomy, phylogeny. Geos 2001:1-109.

MARTINS, L.R., SOUTO, C.A. \& ALVES, O.F.S. 2007a. Diversidade de espécies do Filo Echinodermata nas praias de Salvador, Bahia, Brasil. In: XII Congresso Latino-Americano de Ciências do Mar. (Noberto Olmiro Horn Filho Coord.) Universidade Federal de Santa Catarina, Florianópolis, p.188-189.

MARTINS, L.R., SOUTO, C.A., ALVES, O.F.S. 2007b. Habitats preferenciais da equinodermato fauna de Salvador, Bahia, Brasil. In: XII Congresso Latino-Americano de Ciências do Mar. (Noberto Olmiro Horn Filho Coord.) Universidade Federal de Santa Catarina, Florianópolis, p.188.

MILLOTT, N. 1956. The covering reaction of the sea urchins. 1.A preliminary account of covering in a tropical echinoid Lytechinus variegates (Lamarck), and this relation to light. J. Exper. Biol. 33:508-523.

RODOVALHO, R., GONTIJO, R.C., MILHOMEN, P.S., LIMA, C.C.U. \& MANSO, C.L.C. 2003. Bacias sedimentares brasileiras: Bacia de Cumuruxatiba. Phoenix 5(60):1-4.

SANTA-ISABEL, L.M., CERQUEIRA, W.R.P.C \& ALVES, O.F.S. 1996. Associação entre Ophionereis reticulata (Say, 1825) (Ophiuroidea: Ophionereididae) e Malmgreniella variegata (Treadwell) (Polychaeta, Polynoidea) das praias de Salvador, Bahia, Brasil. Rev. Bras. Zool. 13(1):137-142.

SMITH, A.B. \& BENGTSON, P. 1991. Cretaceous echinoids from northeastern Brazil. Fossils and Strata 31:1-72.
SMITH, A.B.,PATERSON, G.L.J. \& LAFAY, B. 1995. Ophiuroid phylogeny and higher taxonomy: morphological, molecular and palaeontological perspectives. Zool. Jour. Linn. Soc. 114:213-243.

SILVA, E.M., ACCIOLY, M., NAVARRO, M.F.F. \& CHASTINET, C.B.A. 1996. Baía de Todos os Santos: situação atual e perspectivas futuras. Rev. Econ. Nord. 27(2):207-232.

SOUTO, C.A., MARTINS, L.R., ALVES, O.F.S. 2007a. Preferência e comportamento alimentar de Ophioderma cinereum (Echinodermata: Ophiuroidea) Salvador, Bahia, Brasil. In: XII Congresso LatinoAmericano de Ciências do Mar. (Noberto Olmiro Horn Filho Coord.) Universidade Federal de Santa Catarina, Florianópolis, p.187-188.

SOUTO, C.A., MARTINS, L.R., ALVES, O.F.S. 2007b. Ecologia dos Ophiuroidea (GRAY, 1840) (Echinodermata) da praia do farol de Itapuã, Salvador, Bahia, Brasil. In: XII Congresso Latino-Americano de Ciências do Mar. (Noberto Olmiro Horn Filho Coord.) Universidade Federal de Santa Catarina, Florianópolis, p.188.

SOUZA-LIMA, W., MANSO, C.L.C., ANDRADE, E.J. \& GRILLO, J.L. 2003. Bacias sedimentares brasileiras: Bacia de Camamu. Phoenix 5(54):1-6.

SUGUIO, K. 1973. Introdução à sedimentologia. São Paulo, Edgard Blücher, Ed. da Universidade de São Paulo.

TELFORD, M. \& MOOI, R. 1986. Resource partitioning by sand dollars in carbonate and siliceous sediments: Evidence from podial and particle dimensions. Biol. Bull. 169:431-448.

TOMMASI, L.R. 1965. Lista dos Crinóides recentes do Brasil. Contrições Inst. Oceanogr.Univ. S. Paulo, ser. Ocean. Biol. 9:1-33.

TOMMASI, L.R. 1966. Lista dos Equinoides recentes do Brasil. Contrições Inst. Oceanogr.Univ. S. Paulo, ser. Ocean. Biol. 11:1-50.

TOMMASI, L.R. 1970a. Lista dos Asteroides recentes do Brasil. Contrições Inst. Oceanogr.Univ. S. Paulo, ser. Ocean. Biol. 18:1-16.

TOMMASI, L.R. 1970b. Os Ofiuroides recentes do Brasil e de regiões vizinhas. Contrições Inst. Oceanogr. Univ. S. Paulo, ser. Ocean. Biol. 20:1-146.

TOMMASI, L.R. \& ARON, M.A. 1987. Equinodermata dos bancos submarinos da cadeia de montanhas Vitória-Trindade. Relat. Int. Inst. Oceanogr. Univ. São Paulo 18:1-9.

VERRIL, A.E. 1868. Notes of the radiate on the Museum of Yale College, with descriptions of genera and species. 4. Notice on the corals and echinoderms collected by Prof. C.F. Hartt at the Abrolhos Reefs, Province of Bahia, Brazil, 1867. Trans. Conn. Acad. Arts Sci. 1(2):351-371.

Recebido em 14/03/08

Versão reformulada recebida em 31/08/08

Publicado em 23/09/08 